\title{
Syntactic influences on numerical processing in adults: Limited but detectable
}

Krzysztof Cipora*\#1,2,3 https://orcid.org/0000-0003-0077-9336, Hannah D. Loenneker*1 https://orcid.org/0000-0003-0327-6507, Mojtaba Soltanlou ${ }^{1,2}$ https://orcid.org/0000-00031959-1384, Katarzyna Lipowska ${ }^{4}$ https://orcid.org/0000-0003-0702-1560, Frank Domahs ${ }^{5}$ https://orcid.org/0000-0002-5583-4681, Silke M. Göbel ${ }^{6,7}$ https://orcid.org/0000-0001-88456026, Maciej Haman ${ }^{4}$ https://orcid.org/0000-0002-3621-1630, \& Hans-Christoph Nuerk ${ }^{1,2}$

\section{Downloaded from: https://psyarxiv.com/ewtd4/}

${ }^{1}$ Department of Psychology, University of Tuebingen, Tuebingen, Germany

${ }^{2}$ LEAD Graduate School \& Research Network, University of Tuebingen, Tuebingen,

Germany

${ }^{3}$ Centre for Mathematical Cognition, Loughborough University, Loughborough, UK

${ }^{4}$ Department of Psychology, University of Warsaw, Warsaw, Poland

${ }^{5}$ Department of Linguistics, University of Erfurt

${ }^{6}$ Department of Psychology, University of York, York, United Kingdom

${ }^{7}$ Department of Special Needs Education, University of Oslo, Norway

* Equal contribution

\#Corresponding author:

Centre for Mathematical Cognition, Loughborough University, LE 3TU, UK.

Email: k.cipora@lboro.ac.uk

Running head: Syntactic influences on numerical cognition 


\title{
SYNTACTIC INFLUENCES ON NUMERICAL COGNITION
}

\begin{abstract}
In everyday situations, numbers appear in a linguistic context: we communicate and perceive numbers within phrases and sentences. However, languages differ in how they refer to numerosities, and such differences influence number acquisition in children. One of them is in the link between grammatical inflection and specific numbers. Here we asked whether such differences prevail in adults by using the peculiarities of the Polish language. The Polish language is characterized by a complex agreement system between conceptual number and grammatical number: numbers 2-4 require plural grammatical number inflection on the verb while numbers 5-9 require singular inflection. We expected this complex mapping to affect the numerical SNARC (Spatial Numerical Association of Response Codes; i.e., faster left / righthand responses to small / large magnitude numbers, respectively) and grammatical SNARC (i.e., faster left / right-hand responses to singular / plural grammatical forms, respectively) effects at least when grammatical number is made salient. In a task-switching setup, Polish-, German- and English-speaking participants were presented with simple sentences ending in two-digit numbers. Depending on the cue, participants had to judge either the grammatical number of the verb, or the parity status of the number. Surprisingly, no numerical SNARC effect was observed in either task, however a reversed grammatical SNARC effect was found for Polish (but not German and English) in parity judgments. Moreover, only Polish speakers responded faster to parity in the case of grammatically correct sentences. We conclude that grammatical number has a limited, but detectable influence on numerical processing in adults.
\end{abstract}

\section{Words}

Keywords: SNARC effect; grammatical SNARC effect; grammatical number; cross-lingual 


\section{SYNTACTIC INFLUENCES ON NUMERICAL COGNITION}

\section{Introduction}

Languages differ considerably in the ways in which they refer to numbers, and which grammatical structures accompany numbers. Decades of research have shown that these linguistic differences can influence numerical processing at least to some extent. Dowker and Nuerk (2016) proposed a taxonomy of seven levels of linguistic influences on number processing: (a) conceptual; (b) syntactic; (c) semantic; (d) visuo-spatial-orthographic; (e) phonological; (f) other language-related features. Here we focus on the influence of syntactic language differences, which have rarely been studied in adults. Furthermore, partly due to constraints determined by properties of the languages under examination, we explore the impact of language differences at the lexical level.

\section{$\underline{\text { Linguistic specificities }}$}

The grammatical structure beyond the single word level can influence numerical processes specifically for different languages. For example, while cardinal number systems may be functionally identical across cultures, grammatical number systems differ between languages (Corbett, 2000; Sarnecka, 2014). Most languages distinguish singular and plural grammatical forms. Thus, specific morphological forms are used in sentences denoting sets of one or morethan-one entity (e.g., "There is one apple." versus "There are two apples."). Although such grammatical number systems may seem natural for many readers, they are language-specific. Moreover, they matter for numerical development: Children acquiring languages in which a singular-plural distinction is overtly expressed (e.g., English or Russian) acquire exact meanings of the number-words "one" and "two" (and the difference between them) earlier than children, who acquire languages in which such distinctions are not overtly marked (e.g., Japanese; Downing, 1996; Sarnecka et al., 2007; Mandarin; Li, Ogura, Barner, Yang, \& Carey, 2009). Overall, there is substantial evidence that number acquisition is facilitated or hindered by the syntactic specificities of a particular language. 


\section{SYNTACTIC INFLUENCES ON NUMERICAL COGNITION}

Grammatical number continues to influence numerical cognition in adults. For instance, it has been shown that speakers of languages which use grammatical number marking like English judge differences in the number of countable objects (verbalized as count nouns, e.g., apples or cars) as more relevant than differences in the number or amount of non-countable substances (verbalized as mass nouns like milk or sand), in contrast to speakers of languages without grammatical number like Yucatec or Japanese (Athanasopoulos, 2006; Lucy, 1992).

So far, research efforts have focused on differences in numerical development between speakers of languages in which the grammatical number to conceptual number mapping is regular, i.e., where plural forms consistently correspond to larger numbers than singular forms. However, this is not the case for all languages. Several Slavic languages are characterized by specificities in grammatical to conceptual number mapping (Franks, 1994; Sarnecka et al., 2004). Even though the singular / plural markings are present in these languages, mappings between singular and plural forms of both verbs and nouns are not consistently bound to numerically smaller and larger numbers (i.e., Singular: Number 1; Plural: all numbers larger than 1).

Given that grammatical number is tightly associated with the core conceptual number distinction between one (singular) and more than one (plural), this information may be used in the interpretation of connected speech. In fact, some sentences can only be understood unambiguously based on grammatical number interpretation (e.g., Hanne, Burchert, De Bleser, \& Vasishth, 2015). Consider Example 1, taken from Hanne et al. (2015), where verbal number inflection is the only difference between the two sentences, leading to a difference in agentivity:

\section{Example 1}

a) Das Kind schubst $t_{\text {sg }}$ die Tanten. ("The child pushes the aunts.")

b) Das Kind schubsen $\mathrm{pl}$ die Tanten. ("The aunts push the child." Note that word order remained unchanged in German.) 


\section{SYNTACTIC INFLUENCES ON NUMERICAL COGNITION}

When the verb is being processed, its singular or plural marking relates it to one referent (the child) or more than one (the aunts). Thus, in principle, grammatical number allows to make predictions on the number of referents to be expected, limiting the possibilities to one or more than one. In fact, English speaking toddlers are able to use grammatical number (Look, there are some...) to look at an appropriate picture (Kouider, Halberda, Wood, \& Carey, 2006). Similar observations have been reported for other populations, including French speaking toddlers (Robertson, Shi, \& Melançon, 2012) and German adults (Hanne et al., 2015), although grammatical number interpretation may not be consistently observed in younger children (Brandt-Kobele \& Höhle, 2010; Johnson, de Villiers, \& Seymour, 2005) or adults (Riordan, Dye, \& Jones, 2015, see also Davies , Xu Rattanasone, \& Demuth, 2020 for some evidence that such an information might not be consistently used even in some adults).

Moreover, natural languages may contain structures which obscure the relationship between grammatical and conceptual number. For instance, for certain types of nouns, in particular mass nouns or collective nouns (e.g., furniture, news, police, faculty), their grammatical number can be in contrast to their semantic number (Bunt, 2006; Domahs et al., 2012). This frequently leads to agreement errors for grammatical number in speech production (Hokkanen, 1999). However, agreement errors also occur regularly when it comes to interference of grammatical number markings of different elements within a sentence as in "The cost of the improvements *have not yet been estimated.” (Bock \& Miller, 1991).

Generally, grammatical number violations are registered rapidly (Barber \& Carreiras, 2005; Pulvermüller \& Shtyrov, 2003; Wagers, Lau, \& Phillips, 2009), depending on the number and distance of cues at hand (Schweppe, 2013; Tanner \& Bulkes, 2015). We are not aware of any previous evidence, relating conflicting grammatical number cues to the interpretation of conceptual number.

In Polish, in sentences indicating the number of objects, agreement between verb (i.e., predicate), noun (i.e., subject), and numeral is subject to complex rules. In the case of 


\section{SYNTACTIC INFLUENCES ON NUMERICAL COGNITION}

enumerative sentences (e.g., "There are N Xs.”; cf. Table 1 for comparison with English and German), for the number one both noun and verb are singular, and the noun is in the nominative case. For two, three, and four the standard plural syntax is used (with a plural verb and a nominative plural noun). However, for numerals above four, i.e., five to ten, the verb is used in singular and the noun in plural but takes the genitive case. The same happens for two- or moredigit numbers ending with units 2-4 and 5-0, respectively, except for teens and for numbers ending with one, in which the singular verb, plural-genitive noun syntax is used consistently (cf. Table 1). Thus, larger numbers (at the units level) within each decade are typically associated with the singular verb form, while smaller numbers require plural marking on the verb (for more detailed linguistic elaborations on this grammatical construction in Polish and in other Slavic languages see e.g., Derwojedowa et al., 2003; Franks, 1994; Przepiórkowski, 2004, Przepiórkowski et al., 2012; Świdziński, 2015). For the purpose of the current study, the inconsistent mapping between conceptual number and grammatical number of the verb is crucial, which is why sentences consisting of a digit and an inflected verb were used. This is because grammatical number plays an important role in the acquisition of numerical concepts in children. The question arises: does grammatical number also influence numerical representations and processes in adults? As mentioned above, grammatical number marked at the noun can also convey magnitude information. First, there is a distinction between conceptual and grammatical number (inflection), second grammatical number (inflection) appears as verbal number inflection and nominal number inflection. 


\section{SYNTACTIC INFLUENCES ON NUMERICAL COGNITION}

Table 1. Grammatical number systems in Polish, English and German and means by which two-digit number words are constructed in these languages.

\begin{tabular}{|c|c|c|c|}
\hline \multirow{3}{*}{$\begin{array}{l}\text { Cardinal } \\
\text { numbers }\end{array}$} & \multicolumn{3}{|c|}{ Grammatical number, case, and multi-digit number words construction } \\
\hline & \multirow[t]{2}{*}{ Polish } & English & German \\
\hline & & Noun & Noun \\
\hline \multirow[t]{2}{*}{1} & Singular nominative, singular & nominative, singular & nominative, singular \\
\hline & Tam jest jedno jabtko. /There is one apple./ & There is one apple. & Da ist ein Apfel. /There is one apple./ \\
\hline \multirow[t]{2}{*}{$2-4$} & nominative, plural & nominative, plural & nominative, plural \\
\hline & Tam sq dwa jabłka. /There are two apples./ & There are two apples. & Da sind zwei Äpfel. /There are two apples./ \\
\hline \multirow[t]{2}{*}{$5-9$} & $\underline{\text { Singular }}$ genitive, plural $^{\mathrm{a}}$ & nominative, plural & nominative, plural \\
\hline & Tam jest pieć jabtek. /There is five of apples./ & There are five apples. & Da sind fünf Äpfel. /There are five apples./ \\
\hline \multirow[t]{2}{*}{$10-21$} & $\underline{\text { Singular } \quad \text { genitive, plural }}$ & Plural nominative, plural & Plural nominative, plural \\
\hline & Tam jest dziesieć jabtek /There is ten of apples./ & There are ten apples. & Da sind zehn Äpfel. /There are ten apples/ \\
\hline \multirow[t]{2}{*}{$\mathrm{X} 2^{\mathrm{b}}-\mathrm{X} 4$} & Plural nominative, plural & nominative, plural & nominative, plural \\
\hline & $\begin{array}{l}\text { Tam sq dwadzieścia trzy jabtka. /There are twenty- } \\
\text { three apples./ }\end{array}$ & There are twenty-three apples. & $\begin{array}{l}\text { Da sind dreiundzwanzig Äpfel. /There are three-and-twenty } \\
\text { apples./ }\end{array}$ \\
\hline $\mathrm{X} 1$ and & $\underline{\text { Singular } \text { genitive, plural }}$ & nominative, plural & nominative, plural \\
\hline $\mathrm{X} 5-\mathrm{X} 9$ & $\begin{array}{l}\text { Tam jest czterdzieści siedem jabtek. /There is twenty- } \\
\text { seven of apples./ }\end{array}$ & There are forty-seven apples. & $\begin{array}{l}\text { Da sind siebienundvierzig Äpfel. /There are seven-and-forty } \\
\text { apples./ }\end{array}$ \\
\hline
\end{tabular}

${ }^{\mathrm{a}}$ Number ranges, for which there are numerical-grammatical inconsistencies are underlined.

${ }^{\mathrm{b}} \mathrm{X}$ stands for any decade number between 2 and 9.

Inversion between unit and decade number is marked in bold. Note that teen numbers (13-19) are inverted in all languages. Therefore they are not considered in this study. 


\section{SYNTACTIC INFLUENCES ON NUMERICAL COGNITION}

\section{Grammatical structure and the SNARC effect}

Further evidence for the role of grammatical number comes from a study by Roettger and Domahs (2015). Their starting point was the SNARC effect (i.e., Spatial Numerical Association of Response Codes; Dehaene et al., 1993): a phenomenon in left-to-right reading cultures in which small / large magnitude numbers are responded to faster with a left / righthand side button-press respectively, even when the task setup does not explicitly require the processing magnitude of numbers (e.g., if participants are to judge parity status of numbers). This effect has been traditionally been treated as a behavioural signature of semantic number processing (Fias et al., 1996). The implicit (task irrelevant) association of numerical magnitude with directional space (see Cipora et al., 2018; Cipora, Haman et al., 2020) can serve as an interesting indicator of processing of quantity.

Roettger and Domahs (2015) found faster left-hand responses to singular grammatical forms and faster right-hand responses to plural forms of nouns and named this finding the grammatical SNARC effect. Interestingly, the grammatical SNARC effect was modulated by task demands and reaction times. Roettger and Domahs (2015) used German nouns inflected for singular or plural in tasks of surface (visual features: font classification), lexical (classification of stimuli as words or non-words), semantic (categorization as animate creature or inanimate object) and quantity (task relevant quantity information: classification as one entity or more than one) judgement. A reaction time bin analysis, i.e., testing for presence of the grammatical SNARC effect separately within each quartile of participants' reaction times, revealed that the pattern of results differed qualitatively across quartiles indicating an effect of processing depth (Roettger \& Domahs, 2013). A grammatical SNARC effect was present in the quantity tasks for the third and fourth quartile of reaction times. In contrast, for the first quartile in surface, lexical and semantic tasks, the opposite pattern of results was observed. Specifically, singular forms were associated with faster right-hand responses, and plural forms were associated with faster left-hand responses. 


\section{SYNTACTIC INFLUENCES ON NUMERICAL COGNITION}

\section{Grammatical structure and the MARC effect}

The latter observation can be attributed to the MARC effect (linguistic markedness of response codes; Huber et al., 2015; Nuerk et al., 2004). The markedness term was developed in linguistics and refers to an opposition between unmarked forms (e.g., "regular", "certain"), which can be characterised as normal, default, basic, regular or minimum effort forms, and marked linguistic forms, which are outstanding, specific, irregular, complex or uncommon (e.g., "irregular", “uncertain"; see Haspelmath, 2006, for a critical review).

Markedness has also been generalized to morphological forms. Singular forms can be considered unmarked as they are morphologically less complex and typically more frequent, whereas plural forms can be considered marked, given that they are usually more complex and less frequent. The right and left sides can also be considered unmarked and marked, respectively, as the right side is considered basic in numerous cultures (e.g., when people greet, they shake their right hands). Some evidence shows that reactions are facilitated when the markedness of stimuli and responses correspond (Nuerk et al., 2004; Proctor \& Cho, 2006 for response congruity framework without reference to markedness; see also Schroeder, Nuerk, \& Plewnia, 2017). Thus, in the study of Roettger and Domahs (2015) one might have expected faster right-hand responses to singular forms (because both are unmarked) and faster left-hand responses to plural forms (because both are marked). Note that such a grammatical MARC effect goes in the opposite direction from the above-mentioned grammatical SNARC effect for languages like English and German (i.e., grammatical MARC: faster right / left-hand responses

to singular / plural respectively, grammatical SNARC: faster left / right-hand responses to singular / plural respectively).

Roettger and Domahs (2015) concluded that a grammatical SNARC effect may only occur when the task requires semantic quantity processing and / or when it leads to relatively long processing latencies. In tasks which do not require deeper semantic processing and / or 
lead to fast responses the grammatical SNARC effect may be overwritten by a grammatical MARC effect.

$\underline{\text { Inherent grammaticality of numbers }}$

So far, the evidence for a grammatical SNARC effect comes from a within-language study with German-speaking adults, for whom the mapping between singular and plural grammatical forms and quantity representations is straightforward. However, the grammatical SNARC effect demonstrates that grammatical number inflection can evoke similar behavioural signatures as numerical information (i.e., the spatial mapping). Importantly, all the effects of grammatical number inflection referred to above were observed in studies which did not include numbers in any form. It is possible that these signatures also appear when individuals have to process Arabic numbers. For instance, the processing of the number 2 could be associated with faster left hand (indicating the numerical SNARC based on the processing of the magnitude "two") or right hand responses (indicating the indirect grammatical SNARC based on the processing of plurality). In languages with irregular mapping, the numerical and indirect grammatical SNARC effects can be contrasted with each other. For instance, in Polish, if a numerical SNARC effect is present, numbers 2-4 being numerically smaller than numbers 5-9 should be associated with faster left-hand responses, while numbers 5-9 being numerically larger should be associated with faster right-hand responses. However, the numerically smaller numbers (2-4) are at the same time associated with the plural verbal inflection (i.e., plurality, right-hand facilitation), whereas the numerically larger numbers (5-9) are associated with the singular inflection (i.e., singularity, left-hand facilitation; cf. Table 2). Therefore, if the singularity / plurality information is activated (either automatically or induced by the task demands), the indirect grammatical SNARC effect in Polish is predicted to be in the opposite direction than the numerical SNARC effect. In the parity judgement task, participants could have shown either a numerical SNARC (small magnitude numbers $\sim$ LH, large magnitude numbers $\sim \mathrm{RH}$ ) or an indirect grammatical SNARC (Polish only: small magnitude numbers 10 


\section{SYNTACTIC INFLUENCES ON NUMERICAL COGNITION}

RH, large magnitude numbers $\sim \mathrm{LH}$ ) effect. The grammatical number (singular-plural) judgement task could have elicited a direct grammatical SNARC (singular verb LH, plural verb $\sim \mathrm{RH})$ or a grammatical MARC (singular verb $\sim \mathrm{RH}$, plural verb $\sim$ LH) effect. The empirical reaction time patterns can be disentangled as regards the underlying effects when comparing the different language groups (see Table 2).

Therefore, (i) the numerical SNARC effect might be weaker because the indirect grammatical SNARC effect goes in the opposite direction; (ii) vice versa, the indirect grammatical SNARC effect might be weaker because the numerical SNARC effect goes in the opposite direction. For this reason, investigating interactions between numerical and indirect grammatical SNARC effects in languages characterised by irregular mapping seems to be a good candidate for testing influences of less regular grammatical number systems on number processing ${ }^{1}$.

Table 2. Reaction time patterns (faster < slower / slower > faster) for discussed grammatical, numerical and indirect grammatical SNARC and MARC effects in Polish and in two languages characterized with simple grammatical number agreement (English / German).

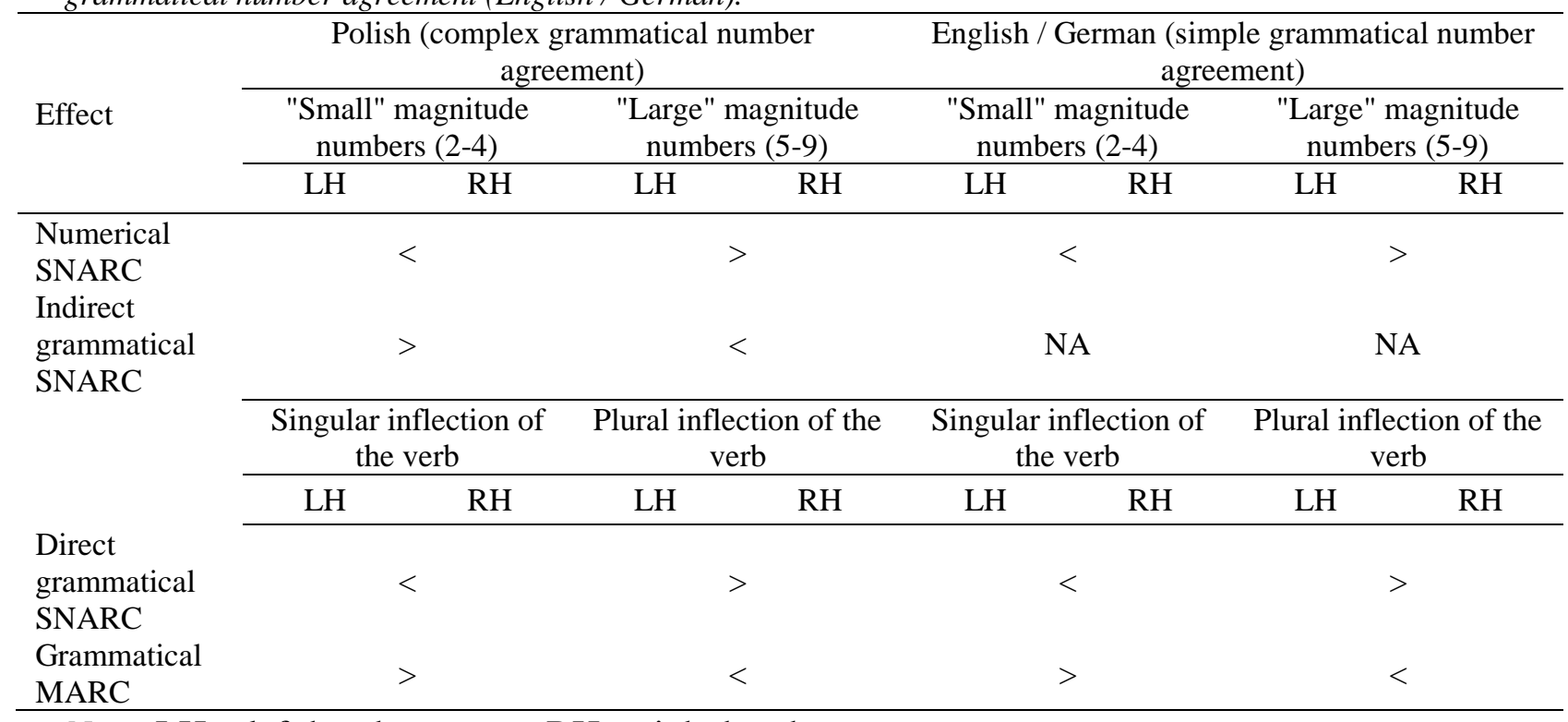

Note. $\mathrm{LH}=$ left hand response, $\mathrm{RH}=$ right hand response.

\footnotetext{
${ }^{1}$ Polish syntax of a grammatical number is actually more complicated, because in addition to the number and case of a noun, the grammatical gender may also change. As a result, for male-personal nouns, the syntax 'singular verb + genitive-plural noun' also applies in the range of numerals ending in 2, 3 and 4, which leads to some level of uncertainty in assessing the correctness of a given form.
} 
By testing this prediction, one can also check the influence of direct grammatical number inflection on numerical processing in adults per se. Importantly, due to the specificities of Polish grammar, testing this prediction is possible for both single- and multi-digit numbers (cf. Table 1). Using the latter may be better suited for testing the effects of syntactic influences on number processing in adults, because multi-digit numbers are less overlearned than singledigit numbers. Thus, multi-digit numerical magnitude representations might be activated less automatically, and therefore possible linguistic influences may be more salient. Importantly, several previous studies have shown that in tasks utilizing two-digit numbers the typical numerical SNARC can be observed in parity judgment. In these studies, the SNARC was more pronounced when unit numbers are considered rather than decade number or overall number magnitude (e.g., Huber et al., 2015; Cipora, Soltanlou, Smaczny, Göbel \& Nuerk, 2019). Therefore, one can safely use it to investigate the effects of grammatical number.

Objectives of the current study

Syntactic influences on numerical cognition can be tested by comparing speakers of languages in which the grammatical number agreement is determined by a complex rule leading to an interference of direct grammatical and numerical SNARC effects (e.g., Polish), to speakers of languages in which the agreement is determined by a simple rule (no interference). For such a language, we will use German, which is the only language for which the direct grammatical SNARC effect has been demonstrated so far.

However, Polish and German languages do not only differ on the syntactic level, but also on the lexical level (Dowker \& Nuerk, 2016). Lexical influences refer to an impact of specific word-level structures used when referring to numbers in different languages. Here, the relevant property is inversion: the order in which decades and units in a two-digit number are named. In inverted languages (e.g., several Germanic languages like Dutch or German), the order of the lexical units in the number words does not follow the order in the Arabic number notation and is also in contrast with the order for larger numbers. For example, the number 27 


\section{SYNTACTIC INFLUENCES ON NUMERICAL COGNITION}

is 'siebenundzwanzig' in German (literally 'seven-and-twenty', see example with bold font for German in Table 1). There is substantial evidence that inversion influences basic numerical processing both in children (Pixner et al., 2011) and in adults (Nuerk et al., 2005, see Nuerk et al., 2015 for a review). For these reasons, cross-lingual lexical influences on numerical processing should not be ignored when designing a cross-lingual experiment. A comparison of Polish and German multi-digit number processing only would not be conclusive, because German and Polish differ both in the grammatical number inflection paradigm (singular vs. plural) and in the lexical properties of number words (inversion vs. non-inversion attributes of number words).

To address this problem and to isolate the influence of syntactic properties from the influence of lexical properties, we used English speakers as an intermediate control group: English does not have an inversion above the teens range (like Polish), and there is a simple rule determining grammatical number agreement (like in German). Therefore, (i) Polish and English only differ in syntactic properties, but not in lexical ones and (ii) English and German only differ in lexical properties, but not in syntactic ones. This allows isolated cross-lingual variation of both syntactic and lexical properties.

The chosen trilingual design has a number of other advantages. First, including the English group allows for a conceptual replication of the direct grammatical SNARC effect in another language, one in which it can be expected to appear, because the grammar of German and English number words does not differ relevantly. A second benefit of including an English group is the ability to investigate possible interplays of syntactic and lexical influences.

Based on the review of the literature above, we can formulate the following predictions:

(1) Numerical SNARC effect:

a) Replicating numerous studies in numerical cognition (Wood et al., 2008 for a metaanalysis, Cipora et al., 2019, for a cross-lingual large-scale study; Huber et al., 2015, Cipora, 
Soltanlou, Smaczny et al., 2019 for two-digit number studies), an overall numerical SNARC effect will be observed in all languages in the parity judgment task.

b) The numerical SNARC effect (in the parity judgment task) will be modulated by the indirect grammatical SNARC effect: it will be weaker in Polish speakers, as numerically larger / smaller numbers are associated with singular / plural number inflection (cf. Table 2).

c) Due to the inversion property, which makes the units more salient (cf. Nuerk et al., 2005), the numerical SNARC effect for units should be more pronounced in German speakers than in English speakers.

(2) Direct grammatical SNARC effect

a) Conceptually replicating Roettger and Domahs (2015), an overall direct grammatical SNARC effect will be observed in the grammatical number (singular-plural) judgment task.

b) The direct grammatical SNARC effect (in the singular-plural judgment tasks) will be modulated by number agreement properties of certain languages: it will be either weaker or reversed in the Polish group, because specific verb forms are associated in an incongruent way with numerical magnitudes (numerically smaller numbers correspond to plural, and numerically larger ones - to singular forms; cf. Table 2).

(3) Interactions between grammatical and numerical information

This hypothesis has a more exploratory character, because to the best of our knowledge, there are no studies or theories that allow for the derivation of direct predictions about the interaction of grammatical and numerical information. However, interactions between grammatical and numerical information may be observed especially in Polish speakers and potentially in both tasks, due to the complex grammatical rules. For instance, there is no strong reason to restrict the direct grammatical SNARC to a singular-plural judgment task only. Roettger and Domahs (2015) assumed that the grammatical SNARC is expected not only in grammatical judgement tasks, but in any task requiring semantic processing. Parity judgment requires semantic processing of the number (Dehaene et al., 1993). Therefore, indirect 


\section{SYNTACTIC INFLUENCES ON NUMERICAL COGNITION}

grammatical number effects may also be observed in the parity judgment task (and being related to singularity / plurality). Vice versa, we have known for a long time that number magnitude (Henik \& Tzelgov, 1982) and its spatial associations can be observed in non-numerical tasks (e.g., Lammertyn, Fias \& Lauwereyns, 2002). Thus, it is conceivable that we may observe SNARC effects even in the grammatical judgment task and it may interact with the complexity and, more specifically, with the spatial associations of grammatical judgement in that primary task. Again, in particular Polish behavioural patterns should differ from English and German data, because Polish grammatical judgement is (i) more complex and (ii) supposedly elicits (in its relation to number) reverse spatial associations.

To sum up, we wish to investigate both (i) the influence of grammatically inflected verb forms on number processing as well as vice versa (ii) the influence of numerical properties on processing of grammatically inflected verb forms and (iii) in a more exploratory fashion, other interactions between numerical and grammatical spatial-numerical associations in a crosslingual format.

\section{Methods}

\section{$\underline{\text { Participants }}$}

A total of 130 (96 females) individuals (mainly university students, and individuals who subscribed to local mailing lists / social media groups for participants) completed the experiment. Nine additional participants did not finish the experiment due to problems with the computerized procedure, or because they wished to stop. Among the individuals who completed the experiment 33 (26 females) were native English speakers, 47 (36 females) were native German speakers, and 50 (34 females) were native Polish speakers. Mean age of participants was $M=22.4$ years, $S D=3.2(M=20.1, S D=1.9, M=23.0, S D=3.3$, and $M=23.3, S D=3.0$ for English, German, and Polish speakers respectively) ${ }^{2}$.

\footnotetext{
${ }^{2}$ During the data collection, we checked the results for accuracy, and continued data collection unless we had > 30 valid participants in each group (see Data preparation and analysis section). Additionally, two Polish 15
} 


\section{SYNTACTIC INFLUENCES ON NUMERICAL COGNITION}

Participants had to meet the following inclusion criteria: (1) native English / German / Polish speaker, (2) Right-handed, (3) No history of neurological or psychiatric disease, (4) No diagnosis of learning disabilities, (5) Normal or corrected-to-normal vision, and (6) No period abroad for longer than one year.

The design of the study was approved by the ethics committees of the University of York, the University of Tuebingen and the University of Warsaw. Participants were compensated by course credit, a small amount of cash, or small gifts in accordance with the rules at the respective universities.

\section{$\underline{\text { Materials }}$}

Parity and grammatical judgement task. In the computerized procedure, participants were presented with phrases comprising a word "there" ("da" and "tam" in German and Polish respectively), a verb either in singular ("is", "ist", "jest" in English, German and Polish respectively) or in plural (“are”, "sind”, "są") operationalizing direct grammatical number and a two-digit number in Arabic notation. For instance, "There is 25", "Da ist 25", "Tam jest 25". In a task-switching setup (i.e., the task changed on a trial-by-trial basis), depending on the cue (either solid or dashed frame around the phrase being presented after $400 \mathrm{msec}$ from phrase presentation onset), they had to judge either the number parity status (odd vs. even), or the grammatical number of the verb (singular vs. plural, direct grammatical number; cf. Figure 1).

participants who turned out not to meet inclusion criteria (1 left-hander and one person with an unspecified neurological or psychiatric diagnosis) were included in the analysis. We double checked their results, and their reaction times were very close to overall sample mean, so we decided to consider them in the analysis. 


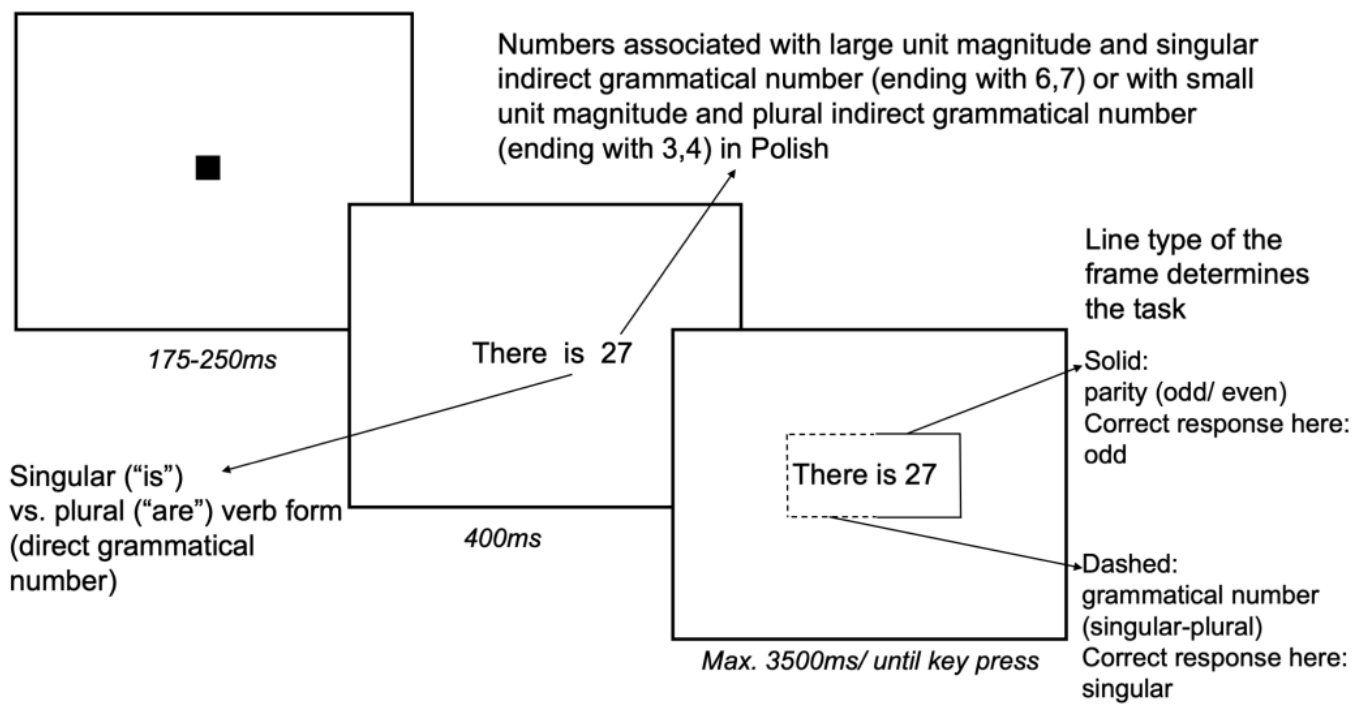

Figure 1. An example of an experimental trial.

Two-digit numbers comprising the unit numbers 3, 4, 6, or 7 combined with decade numbers from two to nine (e.g., 23, 84, 36, 57) were used, yielding 32 different numbers between 23 and 97. In each block, each number $\times$ direct grammatical number $\times$ task type (parity / grammatical number judgment) configuration was repeated twice, which resulted in 256 experimental trials. There were four experimental blocks differing in response-to-key assignment. Therefore, each participant was presented with a total of 1024 experimental trials. The order of the blocks was counterbalanced between participants. Each block was preceded by practice sessions comprising 32 trials. Participants only received feedback on their performance during practice trials with additional prompts concerning the allocation of response keys for singular / plural and odd / even being displayed on the screen. The practice session was repeated if a participant did not reach the accuracy threshold of $80 \%$. In the experimental blocks, there was no feedback and no more prompts about response sides. However, prompt cards indicating the meaning of the frame patterns and the current allocation of response keys were placed next to the laptop, and participants were free to refer to them when needed. Responses were given with keyboard keys A (marked with a blue sticker) on the left and L (marked with a purple sticker) on the right-hand side. All stimuli were presented in 


\section{SYNTACTIC INFLUENCES ON NUMERICAL COGNITION}

black against a light grey background (210 210210 in RGB notation) in Times New Roman font, size 60. The experiment was designed in Presentation ${ }^{\circledR}$ software (Neurobehavioral Systems, 2016) and run on a 14" screen (resolution $1920 \times 1080)$ LENOVO YOGA 700 laptop running Windows 10 OS. The viewing distance was approximately $60 \mathrm{~cm}$. Computerized tasks are available at https://osf.io/yvqxp/.

A number of other questions on other related attributes were administered (see Cipora et al., 2019 for similar control questions). They were not relevant for the question of this manuscript, but can be found in the Supplementary Material A.

\section{Procedure}

Participants were tested individually. After obtaining written informed consent, participants performed the computerised task. Blocks 1 and 3 were followed by obligatory breaks of 30 seconds and an additional break if requested. After block 2, the obligatory break was 1 minute, and afterwards participants filled out the information sheet and were tested on the LPS. Subsequently, the participants were asked to proceed to block three. After completion of the computerized task procedure, participants completed the Speeded Arithmetic Task and the AMAS. The entire experimental session lasted 90 minutes, with the four blocks of the parity and grammatical judgement task adding up to approximately 60 minutes.

\section{Data preparation and Analysis}

Exclusion of participants. Due to the task complexity, 32 participants overall had to be excluded as they did not meet the criterion of $75 \%$ total accuracy in the experimental task, and / or had an accuracy rate below 65\% in any experimental cell (cf. Supplementary material B for detailed information). All participants whose overall accuracy was below 75\%, also met the $65 \%$ exclusion criterion for at least one response-to-task assignment resulting in an overall sample of $N=98(M=22.20, S D=3.40,73$ female $)$ analysed participants. After excluding three participants, in the English sample $N=30(M=20.00, S D=1.84,24$ female $)$ participants 


\section{SYNTACTIC INFLUENCES ON NUMERICAL COGNITION}

were included in the analyses. After excluding 17 participants, the Polish sample consisted of $N=33(M=23.40, S D=3.60,22$ female $)$ participants. In the German sample, 13 participants were excluded resulting in $N=35(M=22.89, S D=3.48,17$ female $)$ participants being analysed.

Inspection of the Supplementary material B shows that most of the exclusions were participants who confused one (or more) response-to-key assignments (i.e., overall high accuracy but very low in one of the assignments). This is because the participants had to keep in mind two response rules at the same time (one about responding to parity, the other about responding to direct grammatical number), and apply them depending on the cue. Furthermore, the rules changed independently of each other between the four blocks. Such participants cannot be included into repeated-measures ANOVA, because their data contains empty cells. Please note that the difference in number of exclusions between language groups can hardly be ascribed to differences in language complexity. For all groups the task was to judge whether the number was odd or even, or whether the verb is singular or plural (i.e., differentiating "is" from "are", "ist" from "sind" and "jest" from "są" in English, German, and Polish respectively). Consequently, the grammatical correctness of the phrase was task-irrelevant, and in all languages, $50 \%$ of phrases were correct and $50 \%$ were incorrect.

Data preparation. In the remaining sample, overall incorrect responses were $7.55 \%$ (7.81\% and $7.30 \%$ for parity and grammatical number judgment respectively; $7.94 \%, 7.01 \%$, 7.78\% for English, German, and Polish participants respectively). Only reaction times (RT) associated with correct responses were further analysed. RTs shorter than $200 \mathrm{~ms}(0.24 \%$ of correctly responded trials) were treated as anticipations and excluded from the RT analysis. In the next step, separately for grammatical number trials and parity judgment trials, RTs being outside \pm 3 SD from the individual mean were excluded sequentially (e.g., Cipora \& Nuerk, 2013; Heubner et al., 2018 for examples of the same procedure in numerical cognition). In the 
end, $88.7 \%$ ( $88.4 \%$ and $88.9 \%$ for parity and singular-plural judgment respectively) of all experimental trials were retained in the analysis.

Data analysis. Data from parity judgment and grammatical judgment trials were analysed separately. Both datasets were analysed by means of the same mixed design ANOVA as specified below:

1. Language: between subjects, three levels: Polish vs. German vs. English

2. Direct grammatical number: within subject, two levels: singular vs. plural

3. Unit magnitude: within subject, two levels: small (and plural indirect grammatical number in Polish), numbers 3 and 4 vs. large (and singular indirect grammatical number in Polish), numbers 6 and 7

4. Response side: within subject, two levels: left vs. right.

Apart from using the classical frequentist approach, for the main effects of interest, we applied Bayesian statistics to be able to provide evidence favouring both alternative and null hypotheses. Here we only report Bayesian analyses on selected contrasts of interests, as there is still no consensus on how to estimate Bayes factors for complex mixed-design ANOVAs (see Wagenmakers et al., 2018). ${ }^{3}$ For the frequentist ANOVA, the significant effects were investigated by follow-up $t$-tests. Effect sizes were determined by means of partial eta squared. To disambiguate the interactions, frequentist (considering effect size measures) and Bayesian $t$-tests over the effects were used.

Crucially, for a numerical SNARC effect to be present, there needs to be a significant interaction of the within-subjects factors response side $\times$ unit magnitude ${ }^{4}$. This can be further

\footnotetext{
${ }^{3}$ However, for completeness of reporting, the full Bayesian ANOVA report can be obtained from https://osf.io/yvqxp/.

${ }^{4}$ Even though the SNARC effect is typically quantified using individual regression slopes (see Fias et al., 1996), using the interaction term is also often used in the literature (see e.g., Huber et al., 2015, Patro et al., 2016). In this case the latter was optimal given that we were interested in the role of the direct and indirect grammatical number in modulating the SNARC effect. However, to make sure that using this method did not cause the null result in the main analyses we used slopes method both for decade and unit numbers, and these analyses did not reveal a significant SNARC either.
} 


\section{SYNTACTIC INFLUENCES ON NUMERICAL COGNITION}

modulated by the (response-irrelevant) grammatical form of the verb and the language. For a direct grammatical SNARC effect to be present in the current data, there needs to be a significant interaction of the within-subjects factors response side $\times$ direct grammatical number. This can be further modulated by the (response-irrelevant) properties of the number and the language.

Analogously to Roettger and Domahs (2013), we conducted an additional RT bin analysis for both tasks, because in their study some effects of interest appeared only, or mainly, in early or late RTs. For each participant, trials were split into four quartile bins, and the analyses described above were run for each bin separately. These analyses are reported in the Supplementary material $C^{5}$. Statistical analyses were run with the R (R core team, 2014), jamovi (Jamovi Project, 2018), and JASP (JASP Team, 2018) software.

\section{Results}

\section{Descriptive results and between-task differences}

Before conducting separate analyses for the parity judgment and the grammatical number judgment tasks we compared the overall performance between tasks and groups. A 2 (task) $\times 3$ (language) mixed-design ANOVA was conducted. Mean RTs were significantly faster for grammatical number judgement $(M=892 \mathrm{~ms}, S E=19.5 \mathrm{~ms})$ than for parity judgement $(M=1008 \mathrm{~ms}, S E=19.5 \mathrm{~ms}), F(1,95)=79.86, p<.001, \eta_{\mathrm{p}}^{2}=.46$. There was no significant main effect of language, $F(2,95)=3.01, p=.054, \eta_{\mathrm{p}}^{2}=.06$ nor task $\times$ language interaction, $F(2,95)=1.87, p=.160, \eta_{\mathrm{p}}^{2}=.04$

\section{$\underline{\text { Parity judgement task }}$}

There was no significant response side $\times$ unit magnitude interaction on the parity judgement task. Thus, and somewhat surprisingly, there was no evidence for the presence of a

\footnotetext{
${ }^{5}$ Results of additional analyses using z-transformed (within participant and condition cells) RTs did not differ from untransformed RT analyses, thus they are not reported here. 
language-independent SNARC effect (Hypothesis 1a not supported, cf. Table 3). Similarly, there was no consistent SNARC when grammatically correct and incorrect phrases were analysed separately. The SNARC effect was also not present when whole number magnitude (both decades and units), and not just unit magnitude was taken into account. Bayesian onesample $t$-test against zero on the difference scores between SNARC compatible and incompatible trials [i.e., RT SNARC incompatible (i.e., LH \{left-hand $\} /$ RH \{right-hand responses to large / small unit magnitude numbers respectively) - RT SNARC compatible (i.e., $\mathrm{LH}$ / RH responses to small / large unit magnitude numbers respectively)] provided conclusive evidence that there was no overall numerical SNARC effect $\left(\mathrm{BF}_{10}=0.11\right)$. The numerical SNARC effect was also not modulated by language as reflected by the non-significant response side $\times$ unit magnitude $\times$ language interaction $(\mathrm{cf}$. Table 3 , thus not supporting Hypotheses $1 \mathrm{~b}$ and 1c). A Bayesian ANOVA on the difference scores between SNARC compatible and incompatible trials (RT SNARC incompatible - RT SNARC compatible) provided conclusive evidence favouring the absence of between-language differences in the numerical SNARC effect $\left(\mathrm{BF}_{10}=0.13\right)$. Effects related to interactions between grammatical and numerical information are discussed below.

Table 3. ANOVA on RTs in parity judgment task.

\begin{tabular}{|c|c|c|c|c|}
\hline Factors & df & $F$ & $p$ & $\eta_{\mathrm{p}}^{2}$ \\
\hline Language & 2,95 & 1.59 & .209 & .03 \\
\hline Direct grammatical number & 1,95 & 2.39 & .125 & .03 \\
\hline Direct grammatical number $\times$ Language & 2,95 & 1.85 & .163 & .04 \\
\hline Response side & 1,95 & 3.56 & .062 & .04 \\
\hline Response side $\times$ Language & 2,95 & 2.17 & .120 & .04 \\
\hline Unit magnitude (Indirect grammatical number) & 1,95 & 0.01 & .938 & .00 \\
\hline Unit magnitude (Indirect grammatical number) $\times$ Language & 2,95 & 0.34 & .716 & .01 \\
\hline Direct grammatical number $\times$ Response side & 1,95 & 4.45 & .037 & .05 \\
\hline Direct grammatical number $\times$ Response side $\times$ Language & 2,95 & 3.29 & .042 & .07 \\
\hline $\begin{array}{l}\text { Direct grammatical number } \times \text { Unit magnitude (indirect grammatica } \\
\text { number) }\end{array}$ & 11,95 & 0.37 & .543 & .00 \\
\hline $\begin{array}{l}\text { Direct grammatical number } \times \text { Unit magnitude }(\text { Indirect } \\
\text { grammatical number } \times \text { Language }\end{array}$ & 2,95 & 4.79 & .010 & .09 \\
\hline Response side $\times$ Unit magnitude (indirect grammatical number) & 1,95 & 0.01 & .945 & .00 \\
\hline $\begin{array}{l}\text { Response side } \times \text { Unit magnitude (indirect grammatical number) } \times \\
\text { Language }\end{array}$ & 2,95 & 0.40 & .671 & .01 \\
\hline $\begin{array}{l}\text { Direct grammatical number } \times \text { Response side } \times \text { Unit magnitude } \\
\text { (indirect grammatical number) }\end{array}$ & 1,95 & 0.50 & .480 & .01 \\
\hline $\begin{array}{l}\text { Direct grammatical number } \times \text { Response side } \times \text { Unit magnitude } \\
\text { (indirect grammatical number) } \times \text { Language }\end{array}$ & 2,95 & 2.00 & .141 & .04 \\
\hline
\end{tabular}


Note. Type III Sum of Squares; Significant effects are marked in bold.

Grammatical number (singular-plural) judgement task

Regarding the grammatical number judgment task, the ANOVA neither showed a significant direct grammatical number $\times$ response side interaction, thus not providing evidence for a direct grammatical SNARC effect in the grammatical number judgement task, nor the presence of a grammatical MARC effect (thus providing no support for Hypothesis 2a). Bayesian one-sample $t$-test against zero on the difference scores between direct grammatical SNARC compatible and incompatible trials [RT direct grammatical SNARC incompatible (i.e., $\mathrm{LH}$ / RH responses to plural and singular direct grammatical number respectively) - RT direct grammatical SNARC compatible (i.e., LH / RH responses to singular and plural direct grammatical number respectively)] provided evidence that supported the null hypothesis $\left(\mathrm{BF}_{10}\right.$ $=0.20)$.

The direct grammatical SNARC effect was also not modulated by language (thus providing no support for Hypothesis $2 \mathrm{~b}$; $\mathrm{cf}$. Table 4). A Bayesian ANOVA on the difference scores between direct grammatical SNARC compatible and incompatible trials [RT direct grammatical SNARC incompatible - RT direct grammatical SNARC compatible] provided conclusive evidence favouring the absence of between-language differences for the direct grammatical SNARC effect $\left(\mathrm{BF}_{10}=0.11\right)$. Effects related to interactions between grammatical and numerical information are discussed below.

Table 4. ANOVA on RTs in singular-plural judgment task.

\begin{tabular}{lllll}
\hline Factors & df & $F$ & $p$ & $\eta^{2} p$ \\
\hline Language & $\mathbf{2 , 9 5}$ & $\mathbf{3 . 9 7}$ & $\mathbf{. 0 2 2}$ & $\mathbf{. 0 8}$ \\
Direct grammatical number & $\mathbf{1 , 9 5}$ & $\mathbf{4 . 8 6}$ & $\mathbf{. 0 3 0}$ & $\mathbf{. 0 5}$ \\
Direct grammatical number $\times$ Language & $\mathbf{2 , 9 5}$ & $\mathbf{3 . 4 6}$ & $\mathbf{. 0 3 5}$ & $\mathbf{. 0 7}$ \\
Response side & 1,95 & 2.53 & .115 & .03 \\
Response side $\times$ Language & $\mathbf{2 , 9 5}$ & $\mathbf{3 . 1 7}$ & $\mathbf{. 0 4 7}$ & $\mathbf{. 0 6}$ \\
Unit magnitude (indirect grammatical number) & 1,95 & 0.88 & .352 & .01 \\
Unit magnitude (indirect grammatical number) $\times$ Language & 2,95 & 1.60 & .208 & .03 \\
Direct grammatical number $\times$ Response side & 1,95 & 1.11 & .295 & .01 \\
Direct grammatical number $\times$ Response side $\times$ Language & 2,95 & 0.24 & .787 & .01
\end{tabular}


Direct grammatical number $\times$ Unit magnitude (indirect grammatical 1,95 number)

Direct grammatical number $\times$ Unit magnitude (indirect grammatical 2, 95 number) $\times$ Language

Response side $\times$ Unit magnitude (indirect grammatical number) $\quad 1,95$

Response side $\times$ Unit magnitude (indirect grammatical number) $\times \quad 2,95$

2,95

Language

Direct grammatical number $\times$ Response side $\times$ Unit magnitude $\quad 1,95$

$0.01 \quad .990 \quad .00$

(indirect grammatical number)

Direct grammatical number $\times$ Response side $\times$ Unit magnitude $\quad 2,95$ (indirect grammatical number) $\times$ Language

Note. Type III Sum of Squares; Significant effects are marked with bold.

Interactions between grammatical and numerical information

Parity judgement. In line with Hypothesis 3, we observed language-dependent interactions between grammatical and numerical effects in the parity judgment task. The direct grammatical number $\times$ response side interaction reached significance (cf. Table 3): a significant difference in RTs between left and right (faster responses to right) was present only for singular $\left(p_{\text {Tukey }}=.027\right.$; there was a marginal difference between singular and plural for the right hand, $\left.p_{\text {Tukey }}=.051\right)$, suggesting either a reverse direct grammatical SNARC effect or a regular grammatical MARC effect. Interestingly this interaction occurred when the participants were judging the parity of a number, not the grammatical form of the verb (cf. Figure 2, upper part for means and CIs). Crucially, this interaction was further qualified by language (significant three-way-interaction, cf. Table 3 and Figure 2 lower part for means and CIs). 


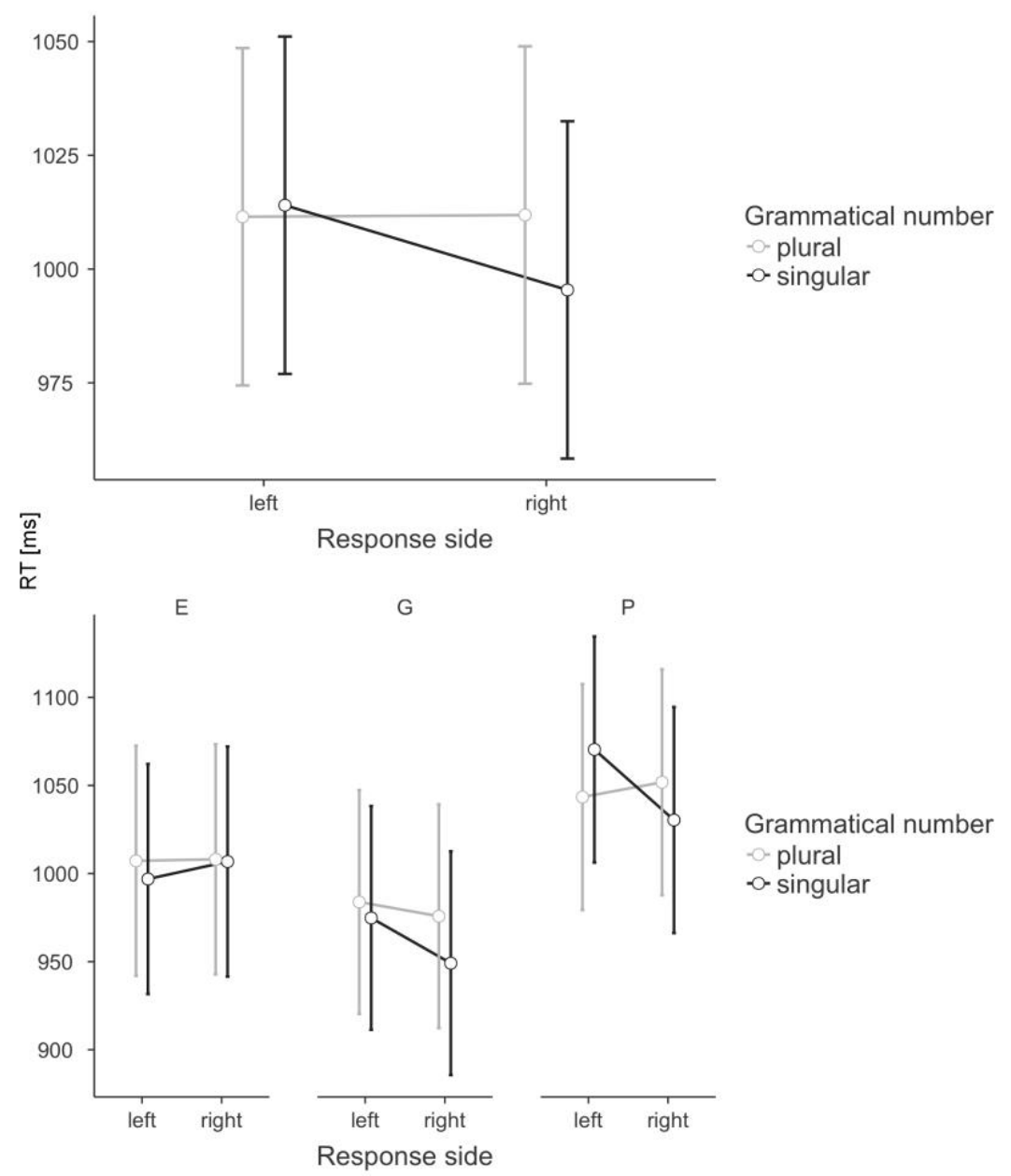

Figure 2. Upper part: Direct grammatical number $\times$ response side interaction in the parity judgment task. This interaction was modulated by language (lower part): For Polish [P] we observed a cross-over interaction indicating a reverse direct grammatical SNARC effect. Such an effect was present neither for German [G] nor for English [E].

To disambiguate this three-way interaction, we calculated the effects for Singular-Plural LH and Singular-Plural RH and compared them with dependent sample $t$-tests for each language separately. Both frequentist and Bayesian $t$-tests were used (to obtain effect size estimates and BFs). For Polish the effect was robust, supporting the cross-over interaction, frequentist $t(32)=3.25, p=.003, d=0.57$. There was also robust Bayesian evidence supporting $\mathrm{H} 1, \mathrm{BF}_{10}=13.39$. The differences were significant neither for German, $t(34)=1.28, p=.208$, $d=0.22$ nor for English, $t(29)=-0.49, p=.627, d=-0.09$, with moderate evidence for H0 in both cases $\left(\mathrm{BF}_{10}=0.39 \text {, and } \mathrm{BF}_{10}=0.22 \text {, respectively }\right)^{6}$. Such a pattern of results may provide

\footnotetext{
${ }^{6}$ Note also, that descriptively Polish participants elicited longer RTs than other groups, but the difference was only significant in one cell. 
some support for associations of indirect grammatical number with space, especially in Polish, where the variation of grammatical numbers is less straightforward and more effortful to process.

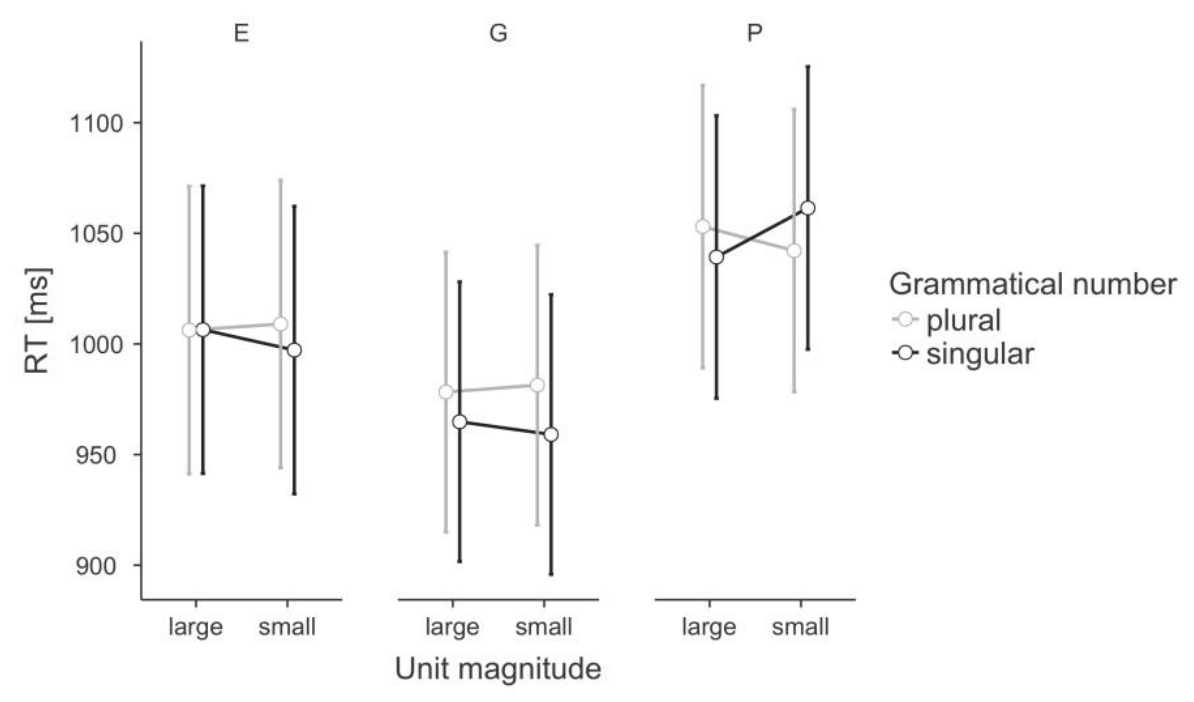

Figure 3. Direct grammatical number $\times$ unit magnitude (indirect grammatical number) $\times$ language interaction in the parity judgment task.

Additionally, the three-way direct grammatical number $\times$ unit magnitude $\times$ language interaction was significant (cf. Figure 3 and Table 3) ${ }^{7}$. The cross-over interaction in Polish revealed that RTs were faster in grammatically correct sentences (i.e., when direct and indirect grammatical number corresponded). Specifically, parity judgments to numbers ending with 6 and 7 (i.e., associated with singular verb form) were faster when these numbers were presented together with the verb in singular. Parity judgments to numbers ending with 3 and 4 (i.e., associated with plural verb form) were faster when the numbers were presented together with the verb in plural. Such an effect of facilitated parity judgments in the case where direct and indirect grammatical number corresponded (i.e., the sentence was grammatically correct) was present neither in English nor in German. Note however that the grammatical correctness is defined differently for Polish (the interaction of unit magnitude with direct grammatical number

\footnotetext{
${ }^{7}$ The above-mentioned interaction remains significant even when the data from Polish participants are compared to collapsed German and English samples. 


\section{SYNTACTIC INFLUENCES ON NUMERICAL COGNITION}

described above) as compared to German and English (a main effect of direct grammatical number - we used only numbers $>1$, correct sentences were always those with plural verb forms). So, for English and German, the grammatical correctness could be inferred solely based on the verb without reference to the number (because plural was always correct and singular always wrong), while for Polish, the specific combination of verb and number had to be evaluated for each sentence.

In order to formally examine whether there was an effect of interest, dependent sample $t$-tests were conducted (frequentist and Bayesian) for effects (singular versus plural for large and small numbers) in Polish and for singular versus plural for German and English ${ }^{8}$. Please note that grammatical correctness is defined differently for the investigated languages (German and English: main effect of direct grammatical number; Polish: interaction unit magnitude $\times$ direct grammatical number).

For Polish, the effect was robust, frequentist $t(32)=2.42, p=.021, d=0.42$. There was also weak Bayesian evidence supporting $\mathrm{H} 1, \mathrm{BF}_{10}=2.32$. For German, the effect was also significant, but in the opposite direction (faster parity judgment responses in the case of grammatically incorrect sentences with singular), frequentist $t(34)=-2.82, p=.007, d=-0.48$. There was also moderate Bayesian evidence supporting $\mathrm{H} 1, \mathrm{BF}_{10}=5.58$. For English the effect was not significant, frequentist $t(29)=-0.65, p=.524, d=-0.12$. There was also moderate Bayesian evidence supporting $\mathrm{H} 0, \mathrm{BF}_{10}=0.24^{9}$.

\footnotetext{
${ }^{8}$ The effect for German and English cannot be accounted for by a simple semantic congruency effect in which parity judgments for singular / plural are faster for numerically small / large numbers because there is no direct grammatical number $\times$ unit magnitude interaction. In other words, there is no difference between singular vs. plural advantage depending on unit magnitude.

${ }^{9}$ To check for the possibility that the four-way interaction was blurred due to null effects for German and English speakers, and that there might be a direct grammatical number $\times$ unit magnitude $\times$ response side interaction for Polish speakers, we repeated the analysis for Polish speakers only. However, this three wayinteraction was not present $(p=.326)$. 
A bin analysis of RT quartiles (see Supplementary material C) within each participant analogous to that used by Roettger and Domahs (2013) did not reveal any consistent results for the numerical SNARC effect and its modulation by language.

Grammatical number judgement. With regards to the less specific influences indicated (i.e., Hypothesis 3), we observed several effects. There was a significant main effect of language, driven by the difference between German and Polish, $p=.006$ (uncorrected, $p=$ .018 Bonferroni-Holm corrected; cf. Figure 4). Furthermore, there was a significant main effect of direct grammatical number, with singular responded to faster than plural (cf. Figure 4).

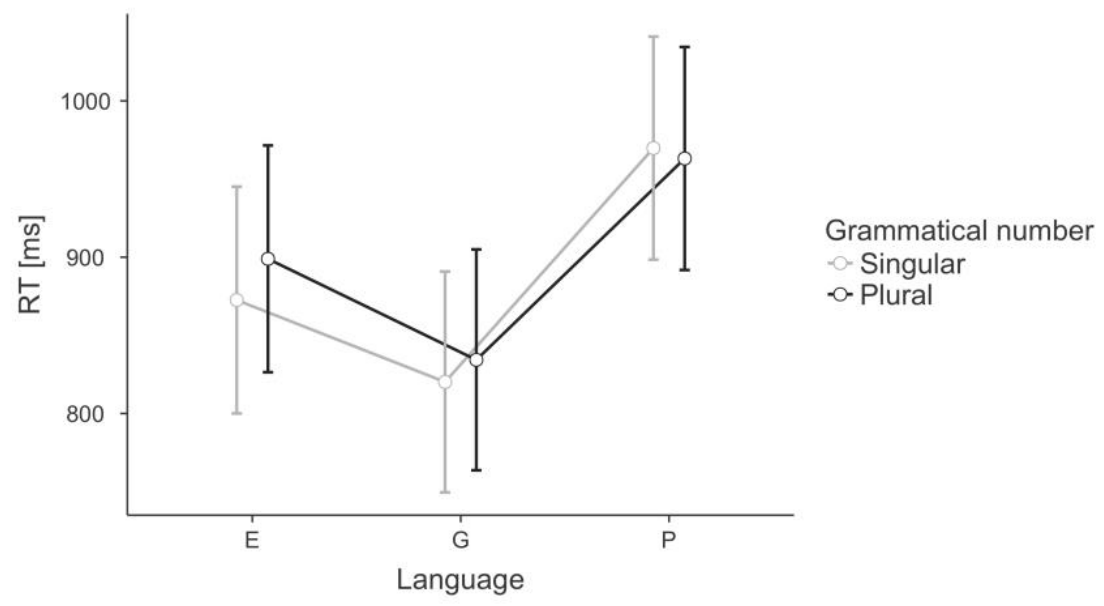

Figure 4. Mean RTs by language group [English (E), German $(G)$, and Polish $(P)$ ] and direct grammatical number in the singular-plural judgment task.

This may reflect a typical main markedness effect (not an interaction like in the MARC effect) because singular is considered the unmarked ground form. There was also a significant interaction of these two factors (cf. Figure 4). Follow-up dependent sample $t$-tests revealed that the difference between singular and plural was only significant for English (uncorrected $p=$ $.008, d=0.52, \mathrm{BF}_{10}=5.37$ ) and German (uncorrected $p=.041, d=0.36, \mathrm{BF}_{10}=1.32$ ) but not for Polish (uncorrected $p=.546, d=-0.11, \mathrm{BF}_{10}=.22$ ) speakers $^{10}$, for which the direct grammatical number decision was more complex, because plural was not always correct.

\footnotetext{
${ }^{10}$ There is no straightforward way to determine the number of possible comparisons and to apply a correction accordingly, so we report uncorrected values here.
} 


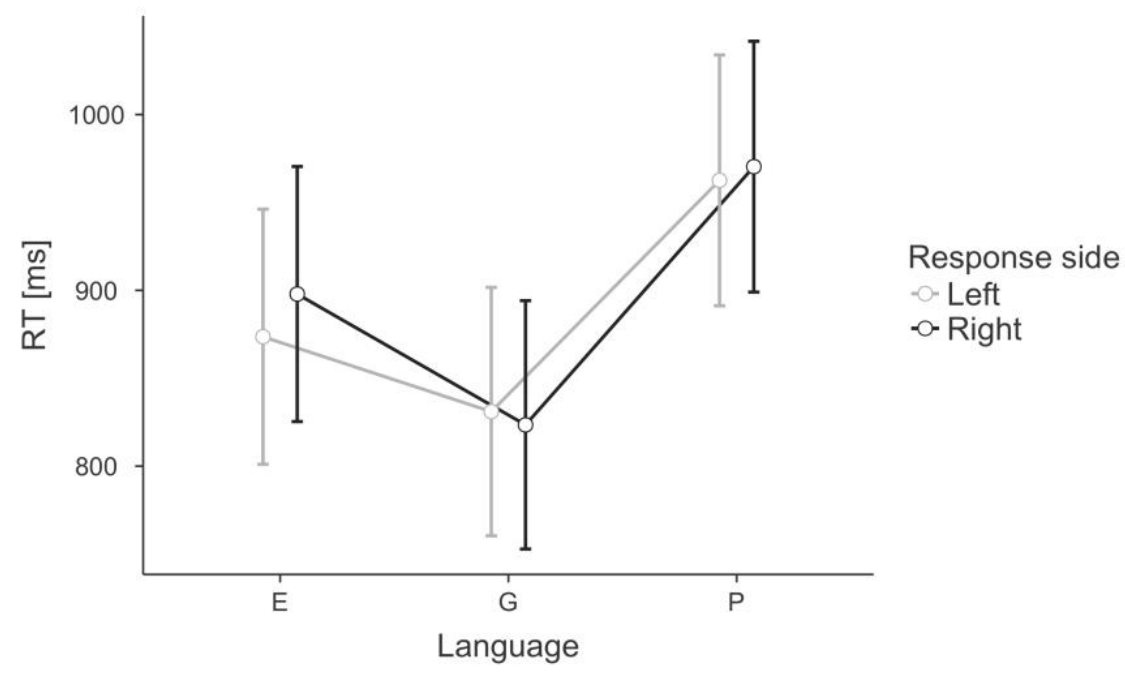

Figure 5. Mean RTs by language group [English $(E)$, German $(G)$ and Polish $(P)]$ and response side in the singular-plural judgment task.

There was also a significant Response side $\times$ Language interaction (cf. Figure 5). Follow-up $t$ tests revealed that English speakers responded faster with the left rather than with the right hand (uncorrected $p=.005, d=-0.55, \mathrm{BF}_{10}=7.70$ ). Neither Polish nor German speakers revealed a significant difference in RTs between right- and left-hand responses (uncorrected $p=.436, d=$ $-0.14, \mathrm{BF}_{10}=0.25$, uncorrected $p=.384, d=0.15, \mathrm{BF}_{10}=0.26$ respectively).

An additional bin analysis of RT quartiles within each participant (Supplementary material C) was aimed at investigating the effects of processing depth. It revealed a significant grammatical MARC effect (or reverse direct grammatical SNARC, i.e., faster right / left-hand responses to singular / plural verbs respectively) among the fastest responses (Bin 1), in other bins the crucial interaction was not significant.

\section{Discussion}

$\underline{\text { Overview }}$

In this study, we investigated (i) syntactic influences on numerical processing in adults with a focus on grammatical number inflection, (ii) lexical (unit-decade inversion) influences and (iii) the interplay between syntactic and lexical influences. Specifically, we investigated 
whether these linguistic factors influence the numerical and grammatical SNARC effects. To pursue this goal, we utilized a task-switching paradigm in which participants were cued for each trial with the information that they had to judge the number parity or direct grammatical number of the verb that was presented. The summary of main findings with reference to hypotheses can be found in Table 5 .

Table 5. Summary of the results with reference to hypotheses.

\begin{tabular}{|c|c|c|}
\hline Hypothesis & Expected effect & Result \\
\hline $1 \mathrm{a}$ & Overall numerical SNARC & Not confirmed \\
\hline $1 b$ & $\begin{array}{l}\text { Numerical SNARC modulated by indirect grammatical } \\
\text { SNARC }\end{array}$ & Not confirmed \\
\hline $1 \mathrm{c}$ & Unit numerical SNARC stronger in German speakers & Not confirmed \\
\hline $2 \mathrm{a}$ & Overall direct grammatical SNARC & Not confirmed \\
\hline $2 b$ & Direct grammatical SNARC modulated by language & Not confirmed \\
\hline 3 & $\begin{array}{l}\text { Interactions between grammatical and numerical } \\
\text { information }\end{array}$ & Confirmed \\
\hline \multirow[t]{2}{*}{$\begin{array}{l}\text { Supplementary } \\
\text { analyses }\end{array}$} & Bin analysis - grammatical number judgment task & $\begin{array}{l}\text { Significant reverse direct } \\
\text { grammatical SNARC in Bin } 1 \\
\text { (fastest responses). }\end{array}$ \\
\hline & Bin analysis - parity judgment task & No significant effects \\
\hline
\end{tabular}

However, despite these null findings in the direct investigations of numerical and grammatical SNARC effects, we did observe other syntactic influences in educated adults. As specified in hypothesis 3, these influences are more nuanced and less straightforward. In the grammatical judgment task, we observed that singular words were responded to faster than plural words, especially in English and German where the relation to the numbers was straightforward (singular was always wrong and plural always correct, while in Polish this was mixed depending on the corresponding number word).

Interestingly, and somewhat surprisingly, we observed syntactic influences on the direct grammatical SNARC effect in the parity judgement task (and not as we initially expected in the grammatical judgment task, where grammar was task-relevant). We observed an inverse direct grammatical SNARC effect (i.e., singular being responded to faster with the right hand) overall. This inverse direct grammatical SNARC effect was, however, only observed for Polish where direct grammatical number and numerical magnitude of the unit are linked to each other. 


\section{SYNTACTIC INFLUENCES ON NUMERICAL COGNITION}

However, it was not present either for German or for English, where there was no such link in our stimuli (as all used numbers here were $>1$ ). Additionally, a three-way direct grammatical number $\times$ unit magnitude $\times$ language interaction suggested that in the Polish group response times were faster in grammatically correct sentences (i.e., when direct and indirect grammatical number corresponded). Such an effect of facilitated parity judgments in the case of grammatical number agreement (i.e., the sentence was grammatically correct) was present neither for English nor for German. In general, syntactic effects on indirect grammatical number in the parity judgement task were almost only observed for Polish, where number magnitude and indirect grammatical number are specifically linked, but not for other languages, where no such link exists (because all two-digit numbers are associated with plural).

We will interpret these results from frequentist and Bayesian analyses with care, given the context, in which some other expected effects were absent. The overall observed effect sizes were fairly small which might be due to task complexity. Therefore, our findings might guide future investigations potentially utilizing simpler and more controlled designs to better understand the role of grammatical number processing in numerical cognition in different languages.

\section{$\underline{\text { Syntactic influences on number processing }}$}

The grammatical correctness of the sentence (i.e., grammatical number agreement) affected parity judgments differently in the three language groups. They did neither affect the numerical SNARC effect directly in the parity judgement task nor the direct grammatical SNARC effect in the grammatical judgment task, but surprisingly indirect grammatical effects in the parity judgement task were observed. This was the case almost only for Polish, the language in which the grammatical correctness of sentences used in the task was determined by specific configurations of verb inflection and unit magnitude, here a facilitation effect (i.e., faster parity judgments in the case of grammatically correct sentences) was observed. The only exception was German, in which grammatical correctness of sentences used in the task was 


\section{SYNTACTIC INFLUENCES ON NUMERICAL COGNITION}

determined by the presence or absence of a verb in its plural form, here faster responses were observed when the irrelevant unmarked singular verb was presented. For English, the direction of the effect was the same as for German, but the effect was not significant. ${ }^{11}$ This can be interpreted as a main effect of morphological markedness. As outlined in the introduction, singular forms can be considered unmarked as they are morphologically less complex and typically more frequent, whereas plural forms can be considered marked, given that they are usually more complex and less frequent. Our finding is consistent with this notion of morphological markedness generalized to morphological forms.

However, no such simple markedness main effect was observed in Polish. We suggest that complex rules for direct grammatical number, which are determined by the relation of number magnitude and indirect grammatical number, made the otherwise identical task a more complex task for the Polish participants. This might also have affected cognitive processing in the single tasks and led to the null effects.

Another surprising finding regarding the language effects related to (task-irrelevant) grammatical verb forms observed in the parity judgment task were faster responses to trials with singular verbs on the right-hand side and to trials with plural verbs on the left-hand side. This effect was present for Polish but not for English and German. The pattern of results observed for Polish may be due to a standard grammatical MARC effect as initially outlined by Roettger and Domahs (2015): more basic (i.e., unmarked) singular forms are associated with the more basic (i.e., unmarked) right-hand response (see also Huber et al., 2015). However, if this were the case, a similar effect should also be observed for German and English ${ }^{12}$. Nevertheless, we did not observe a grammatical MARC effect in German and English.

\footnotetext{
${ }^{11}$ Due to inversion, the parity information might be easier to access in German, because the unit relevant for parity is spoken first. Therefore, the primary task may be even easier and more automatic in German, which might make the irrelevant morphological markedness effect stronger than in English, where it went in the same direction, but was not significant.

${ }^{12}$ Note that, some Polish linguists (e.g. Dziwirek, 1990) indicate that the third person singular neuter form of the verb is the default plural syntax for numerals above "1".
} 


\section{SYNTACTIC INFLUENCES ON NUMERICAL COGNITION}

Moreover, the grammatical MARC effect may be diminished due to the morphological forms in all three languages used in the current study, e.g., the plural of the verb "to be" is not a suffixed form of the singular form (as was the case for nouns used by Roettger and Domahs, 2015), but is a separate (suppletive) morphological form (i.e., is - are, ist - sind, jest - są).

Nevertheless, we need to understand why such a grammatical MARC effect was observed for Polish. For such an explanation it is important to note that in the present study the singular / plural distinction is probably not very salient for German and English because all number words are typically associated with plural indirect grammatical number (that is the default for all numbers > 1). To (automatically) process the sentence correctness (even though it was not enforced by the task instructions) it was sufficient to recognize the verb form: Plural was always correct and singular was always wrong in German and English. This was highly predictable and without exception throughout the experiment. This was dramatically different for Polish. Fifty percent of singular and plural sentences were correct and 50\% were incorrect, thus their correctness depended not only on the verb itself, but on the agreement between verb (grammatical number) and number (unit magnitude). One might suppose that this unique relationship between grammatical number and unit number magnitude may lead to grammatical number effects for Polish when unit magnitude is task relevant. The processing of number agreement violations seems to take into account the number of cues (Tanner \& Bulkes, 2015). This resembles our situation, where there are several, in the case of Polish sometimes conflicting cues to conceptual number.

A second, and more appealing, explanation for the result pattern for Polish is that the effect was due to a reversed direct grammatical SNARC effect. This could be inferred from the specificity of the Polish enumerative syntax (a singular verb form signals larger numerical magnitudes). Specifically, as laid out in the introduction in the natural linguistic context, singular verb forms are generally associated with numerically larger numbers (e.g., 5-9) and plural forms to numerically smaller numbers (e.g., 2-4) with the number 1 being the only 


\section{SYNTACTIC INFLUENCES ON NUMERICAL COGNITION}

exception. Thus, Polish speakers may have a highly overlearned association of the singular verb form with larger magnitudes and the plural verb form with smaller magnitudes. If this association of grammatical number with numerical magnitude drives Polish speakers' responses, a reverse direct grammatical SNARC effect is to be expected. This interpretation is also fully consistent with the absence of this effect for English and German, because all numbers used were associated with the plural form (number 1 was not used in this experiment). Finally, the variations in the time course are also consistent with this account: According to Roettger \& Domahs (2013) processes producing a direct grammatical SNARC effect are slower and less automatic than those involved in generating a MARC effect. Relatively slow processing of direct grammatical number in the direct grammatical SNARC effect does not require a salient marking of number. When we take a closer look at the bin analysis, we observe a direct grammatical number $\times$ response side interaction in bin 2, i.e., a weak reversed MARC effect for all three languages, which supports the absence of a standard MARC effect. The early bins, in which MARC effects are prevalent, show an interaction in the opposite direction to that what we have observed overall in this experiment (where we observed a regular grammatical MARC and a reversed direct grammatical SNARC for Polish). Thus, the timing of the different effects also supports the conclusion that the overall advantage for right-hand responses to the number in context of the singular verb in Polish is more likely to indicate a reversed direct grammatical SNARC effect than the presence of a grammatical MARC effect.

It is not possible to conclusively decide between these alternatives on the basis of our data. However, some results of the bin analysis interpreted together with the same analyses of Roettger \& Domahs (2015) seem to suggest that the reversed direct grammatical SNARC account is somewhat more consistent with the time course of the data than the morphological MARC account.

Last but not least, a very recent study (Davies et al., 2020) shows that at least some English-speaking adults do not consider the grammatical inflection of the verb even if it 


\section{SYNTACTIC INFLUENCES ON NUMERICAL COGNITION}

provides direct task-relevant information on how to interpret numerosity. This new finding shows some limitations on how spontaneously and automatically singularity and plurality are extracted from grammatical forms (see e.g., Berent et al., 2005 for evidence of automaticity). These new findings need to be considered especially in future cross-linguistic comparisons.

\section{Failed (conceptual) replications}

As one might already infer from above considerations, the failure to replicate the wellestablished numerical SNARC effect (see Cipora et al., 2019; Wood et al., 2008 for a metaanalysis; Huber et al., 2015; Cipora, Soltanlou, Smaczny et al., 2019; Weis, Nuerk, \& Lachmann, 2018 for two-digit number studies), and the less investigated direct grammatical SNARC effect (Roettger \& Domahs, 2015) in the grammatical judgement task must be looked at in a more differentiated manner. As we already showed in previous publications that there are no differences between German and Polish samples with regards to the single-digit SNARC effect (Cipora, Soltanlou, Reips, \& Nuerk, 2019, see Supplementary Material there), we did expect to find a SNARC effect in the different language groups.

We have discussed the results of our bin analysis in detail above when we considered the reversed direct grammatical SNARC account of our findings. Therefore, we will now focus mostly on the lack of numerical and grammatical SNARC effects in the numerical and grammatical tasks, respectively. In particular, the failure to replicate the numerical SNARC effect, which has been replicated multiple times, is striking, given that the Bayesian analyses suggest that we did not have a power problem in our study.

Keeping in mind methodological and linguistic differences between the present study and typical setups used for investigating numerical and grammatical SNARC effects, this experiment should be considered as a conceptual rather than a direct replication (Simons, 2014). Several methodological and linguistic differences might account for the lack of grammatical and numerical SNARC effects. 
Multiple spatial codes and inhibition demands. According to a recent theoretical model (Cipora, He, \& Nuerk, 2019), the SNARC effect is a result of (a) automatic semantic processing of numbers, (b) associating it with space, and (c) inhibition and control of interference. Associating numbers with space as well as inhibition and control of interference were altered in the current setup compared to typical experiments. Associating numbers with space could be affected by the activation of multiple spatial codes within a single block: (a) numerical magnitude, (b) direct grammatical number, and (c) for Polish only the indirect grammatical number, which was in opposition to the numerical magnitude code. Furthermore, inhibition and control of interference could be affected by the task load: the participants had to switch between parity and grammatical judgements on a trial-by-trial basis. Similar distortion could also be the case for the direct grammatical SNARC effect.

Working memory load. Another possible explanation for the lack of observations is that working memory of the participants did not have enough capacity for spatial-numerical associations to be evoked. The alternating tasks used here were quite demanding on working memory, as participants needed to keep the response-to-key assignments in working memory for both tasks (Monsell, 2003). It is likely that participants started processing stimuli for both task types simultaneously until they received the cue in the form of the dashed or solid frame which caused conflict between competing responses (Notebaert \& Verguts, 2008). Importantly, the SNARC effect measured with parity judgment disappears under verbal working memory load (van Dijck and Fias, 2011).

Situated influences. The numerical SNARC effect is very prone to multiple situated influences e.g., stimuli set being used or specific task requirements (see Cipora et al., 2018 for a review). The same might hold true for the direct grammatical SNARC effect. As demonstrated by Roettger and Domahs (2015), even within one individual, and within the same task, the effect might either be present or absent depending on which quartile of response times is analysed. 
Linguistic factors. Some factors related to linguistic differences were inherent to the design of our study, which could have hindered the effects of grammar. On one hand, the verb "to be" used in the task sentences has very different (non-cognate) word forms for singular and plural in all three languages (i.e., suppletion). On the other hand, no suffixation applies here, i.e. no distinct morphological marker is added at the end of the word. Thus, "to be" is a frequently encountered and highly overlearned word in all three languages and its singular and plural forms are formally unrelated. Therefore, they might not trigger singular and plural grammatical magnitudes like other morphological variations of more regular and less frequently encountered verbs.

Language differences: grammatical correctness and its complexity. We have used a quasi-experimental design: the between subject variable - language - could not be manipulated. While the material was numerically and semantically matched, the differences in the complexity of the rules determining grammatical correctness of sentences, which we examined, is one of the most vivid differences between languages. Increased complexity in Polish may have evoked more thorough processing of the material. Therefore, faster reaction times for English and German to consistently grammatically incorrect singular sentences can be explained by automatized lexical disagreement detection. This detection is more complex in Polish due to multiple linguistic features that have to be taken into consideration (as in Barber \& Carreiras, 2003). However, such an effect would not be specific to direct grammatical number, but rather might reflect general principles of cognition. So, some specific differences between languages might be explained by domain-specific linguistic features, while others (such as slower reaction times for Polish) might be explained by domain-general processes, which are triggered by the higher complexity of the task in Polish.

In sum, linguistic restrictions being inherent to the language structure may have made the experimental processing of morphology less salient than we expected and prevented effects in the grammatical judgement task. 


\section{Conclusion}

The current study showed that specific syntactic linguistic features, namely grammatical number, can influence number processing in educated adults. Nevertheless, these influences were not straightforward, and were mostly present when the grammatical structure was taskirrelevant. Crucially, they were present only in the Polish language, where the grammatical structure is linked in a complex way to the numerical magnitude of the number, but not in English and German, where grammatical number is the same (plural) for all two-digit number words. In contrast to the observed syntactic effects, we observed almost no lexical effects in this study. Whether the corresponding number words are inverted or not almost never influenced processing in parity judgement or grammatical judgement.

It is important to acknowledge that we used a task-switching paradigm, in which a cue informed the participant on each trial which of the two tasks had to be performed. The numerical SNARC effect in parity judgement could not be replicated in the task-switching setting. However, this failure to replicate is consistent with recent findings that the SNARC effect depends critically on attentional focus and inhibitory control (see Cipora, He, \& Nuerk, 2020), which are probably reduced in the current task setting.

In summary, we found influences of syntax on number processing in adults, which are, however, limited and not as ubiquitous as we had predicted. In future investigations, it will be important to address the boundary conditions for observing such (limited) effects of syntactic structure on number processing.

\section{Acknowledgements}

We would like to thank all participants. Finally, we thank our assistants who helped with data collection and language proofreading the manuscript. 
SYNTACTIC INFLUENCES ON NUMERICAL COGNITION

\section{Conflict of interest statement}

The author declares that the research was conducted in the absence of any commercial or financial relationships that could be construed as a potential conflict of interest.

\section{Funding}

This research was funded by a grant from the DFG (NU 265/3-1) to H-CN supporting KC and MS, and from the National Science Centre, Poland (2014/15/G/HS6/04604) to MH supporting KL. KC, MS, and H-CN are further supported by the LEAD Graduate School \& Research Network (GSC1028), which is funded within the framework of the Excellence Initiative of the German federal and state governments. 


\section{References}

Athanasopoulos, P. (2006). Effects of the grammatical representation of number on cognition in bilinguals. Bilingualism: Language and Cognition, 9(1), 89-96.

Barber, H., \& Carreiras, M. (2003). Integrating Gender and Number Information in Spanish Word Pairs: An Erp Study. Cortex, 39(3), 465-482. https://doi.org/10.1016/S0010-9452(08)70259-4

Barber, H., \& Carreiras, M. (2005). Grammatical gender and number agreement in Spanish: an ERP comparison. J.Cogn Neurosci., 17(1), 137-153.

Berent, I., Pinker, S., Tzelgov, J., Bibi, U., \& Goldfarb, L. (2005). Computation of semantic number from morphological information. Journal of Memory and Language, 53(3), 342-358. https://doi.org/10.1016/J.JML.2005.05.002

Bock, K., \& Miller, C. A. (1991). Broken agreement. Cognitive Psychology, 23(1), 45-93.

Brandt-Kobele, O.-C., \& Höhle, B. (2010). What asymmetries within comprehension reveal about asymmetries between comprehension and production: The case of verb inflection in language acquisition. Lingua, 120(8), 1910-1925.

Bunt, H. C. (2006). Mass Expressions. (Keith Brown, Hrsg.) Encyclopedia of Language \& Linguistics. Oxford: Elsevier.

Cipora, K., Haman, M., Domahs, F., \& Nuerk, H.-C. (2020). Editorial: On the Development of Space-Number Relations: Linguistic and Cognitive Determinants, Influences, and Associations. Frontiers in Psychology, 11, 1-5. https://doi.org/10.3389/fpsyg.2020.00182

Cipora, K., He, Y., \& Nuerk, H.-C. (2020). The Spatial Numerical Association of Response Codes effect and math skills: why related?. Annals of the New York Academy of Sciences, 1477, 5-19. https://doi.org/10.1111/nyas.14355

Cipora, K., Patro, K., \& Nuerk, H.-C. (2018). Situated influences on spatial-numerical associations. In T. Hubbard (Ed.), Spatial Biases in Perception and Cognition (pp. 41-59). https://doi.org/https://doi.org/10.1017/9781316651247.004

Cipora, K., \& Nuerk, H.-C. (2013). Is the SNARC Effect Related to the Level of Mathematics? No Systematic Relationship Observed despite More Power, More Repetitions, and More Direct Assessment of Arithmetic Skill. Quarterly Journal of Experimental Psychology, 66(10), 1974-1991. https://doi.org/10.1080/17470218.2013.772215

Cipora, K., Schroeder, P. A., Soltanlou, M., \& Nuerk, H.-C. (2018). More space, better mathematics: Is space a powerful tool or a cornerstone for understanding arithmetic? In K. S. Mix \& M. T. Battista (Eds.), Visualizing Mathematics. Research in Mathematics Education (pp. 77-116). Springer, Cham. https://doi.org/10.1007/978-3-319-98767-5_4

Cipora, K., Soltanlou, M., Smaczny, S., Göbel, S. M., \& Nuerk, H.-C. (2019). Automatic place-value activation in magnitude-irrelevant parity judgement. Psychological Research. https://doi.org/10.1007/s00426-01901268-1

Cipora, K., Soltanlou, M., Reips, U.-D., \& Nuerk, H.-C. (2019). The SNARC and MARC effects measured online: Large-scale assessment methods in flexible cognitive effects. Behavior Research Methods 51(4):1676, 2019. https://doi.org/10.3758/s13428-019-01213-5

Corbett, G. G. (2000). Number (C. U. Press, Ed.). New York, NY.

Davies, B., Xu Rattanasone, N., \& Demuth, K. (2020). Comprehension of the copula: preschoolers (and sometimes adults) ignore subject-verb agreement during sentence processing. Journal of child language, 47, 695-708. doi:10.1017/S0305000919000680

Dehaene, S., Bossini, S., \& Giraux, P. (1993). The mental representation of parity and number magnitude. Journal of Experimental Psychology: General, 122(3), 371-396. https://doi.org/10.1037/00963445.122.3.371 
Derwojedowa, M., Rudolf, M., \& Swidzinski, M. (2003). Two formal approaches to Polish numeral phrases implemented.[in:] Studia z gramatyki i leksykologii jezyka polskiego. Uniwersytet Mikołaja Kopernika, Torun, 93-108.

Domahs, F., Nagels, A., Domahs, U., Whitney, C., Wiese, R., \& Kircher, T. (2012). Where the Mass Counts: Common Cortical Activation for Different Kinds of Nonsingularity. Journal of Cognitive Neuroscience, 24(4), 915-932.

Dowker, A., \& Nuerk, H.-C. (2016). Editorial: Linguistic Influences on Mathematics. Frontiers in Psychology, 7, 1035. https://doi.org/10.3389/fpsyg.2016.01035

Downing, P. A. (1996). Numeral classifier systems: the case of Japanese (4th ed.). Amsterdam: John Benjamins Publishing.

Dziwirek, K. (1990). Default agreement in Polish. In K. Dziwirek, P. Farrel, \& E. Majías-Bikandi (Eds.), Grammatical Relations (pp. 147-161), Stanford: CSLI Publications.

Fias, W., Brysbaert, M., Geypens, F., \& D’Ydewalle, G. (1996). The importance of magnitude information in numerical processing: Evidence from the SNARC effect. Mathematical Cognition, 2(1), 95-110. https://doi.org/10.1080/135467996387552

Franks, S. (1994). Parametric properties of numeral phrases in Slavic. Natural Language \& Linguistic Theory, 12(4), 597-674.

Hanne, S., Burchert, F., De Bleser, R., \& Vasishth, S. (2015). Sentence comprehension and morphological cues in aphasia: What eye-tracking reveals about integration and prediction. Journal of Neurolinguistics, 34, 83-111.

Haspelmath, M. (2006). Against markedness (and what to replace it with). Journal of Linguistics, 42(1), 25-70. https://doi.org/10.1017/S0022226705003683

Henik, A., \& Tzelgov, J. (1982). Is three greater than five: The relation between physical and semantic size in comparison tasks. Memory \& Cognition, 10(4), 389-395.

Heubner, L., Cipora, K., Soltanlou, M., Schlenker, M.-L., Lipowska, K., Göbel, S. M., ... Nuerk, H.-C. (2018). A Mental Odd-Even Continuum Account: Some Numbers May Be "More Odd" Than Others and Some Numbers May Be "More Even" Than Others. Frontiers in Psychology, 9, 1081. https://doi.org/10.3389/fpsyg.2018.01081

Hokkanen, T. (1999). One or More: Psycholinguistic Evidence for Divergence of Numerosity and Grammatical Number Assignment. Brain and Language, 68, 151-157.

Hopko, D. R., Mahadevan, R., Bare, R. L., \& Hunt, M. K. (2003). The Abbreviated Math Anxiety Scale (AMAS). Assessment, 10(2), 178-182. https://doi.org/10.1177/1073191103010002008

Huber, S., Klein, E., Graf, M., Nuerk, H.-C., Moeller, K., \& Willmes, K. (2015). Embodied markedness of parity? Examining handedness effects on parity judgments. Psychological Research, 79(6), 963-977. https://doi.org/10.1007/s00426-014-0626-9

Jamovi Project. (2018). jamovi.

JASP Team. (2018). JASP.

Johnson, V. E., de Villiers, J. G., \& Seymour, H. N. (2005). Agreement without understanding? The case of third person singular /s/. First Language, 25(3), 317-330.

Kouider, S., Halberda, J., Wood, J., \& Carey, S. (2006). Acquisition of English Number Marking: The SingularPlural Distinction. Language Learning and Development, 2(1), 1-25.

Kreuzpointner, L., Lukesch, H., \& Horn, W. (2013). Leistungsprüfsystem 2. LPS-2. Manual. Retrieved from https://epub.uni-regensburg.de/27958/

Lammertyn, J., Fias, W., \& Lauwereyns, J. (2002). Semantic influences on feature-based attention due to overlap of neural circuits. Cortex, 38(5), 878-882. http://dx.doi.org/10.1016/S0010-9452(08)70061-3 
Li, P., Ogura, T., Barner, D., Yang, S. J., \& Carey, S. (2009). Does the conceptual distinction between singular and plural sets depend on language? Developmental psychology, 45(6), 1644.

Lucy, J. A. (1992). Grammatical categories and cognition: A case study of the linguistic relativity hypothesis. Cambridge: Cambridge University Press.

Monsell, S. (2003). Task switching. Trends in Cognitive Sciences, 7(3), 134-140. https://doi.org/10.1016/S13646613(03)00028-7

Neurobehavioral Systems. (2016). Presentation Software, Version 19.0.

Notebaert, W., \& Verguts, T. (2008). Cognitive control acts locally. Cognition, 106(2), 1071-1080. https://doi.org/10.1016/J.COGNITION.2007.04.011

Nuerk, H.-C., Iversen, W., \& Willmes, K. (2004). Notational Modulation of the SNARC and the MARC (Linguistic Markedness of Response Codes) Effect. The Quarterly Journal of Experimental Psychology Section A, 57(5), 835-863. https://doi.org/10.1080/02724980343000512

Nuerk, H.-C., Weger, U., \& Willmes, K. (2005). Language effects in magnitude comparison: Small, but not irrelevant. Brain and Language, 92(3), 262-277. https://doi.org/10.1016/J.BANDL.2004.06.107

Nuerk, H.-C., Moeller, K., \& Willmes, K. (2015). Multi-digit number processing: overview, conceptual clarifications, and language influences. In R. Cohen Kadosh,. A. Dowker (Ed.), The Oxford Handbook of Numerical Cognition (pp. 106-139). Oxford: Oxford University Press.

Patro, K., Fischer, U., Nuerk, H.-C., \& Cress, U. (2016). How to rapidly construct a spatial-numerical representation in preliterate children (at least temporarily). Developmental Science, 19(1), 126-144. https://doi.org/10.1111/desc. 12296

Pixner, S., Moeller, K., Hermanova, V., Nuerk, H.-C., \& Kaufmann, L. (2011). Whorf reloaded: language effects on nonverbal number processing in first grade-A trilingual study. Journal of Experimental Child Psychology, 108(2), 371-382.

Proctor, R. W., \& Cho, Y. S. (2006). Polarity correspondence: A general principle for performance of speeded binary classification tasks. Psychological Bulletin, 132(3), 416-442. https://doi.org/10.1037/00332909.132.3.416

Przepiórkowski, A. (2004). O wartości przypadka podmiotów liczebnikowych. Biuletyn Polskiego Towarzystwa Językoznawczego, LX, 133-143.

Przepiórkowski, A., Patejuk, A., (2012). The puzzle of case agreement between numeral phrases and predicative adjectives in Polish. In M. Butt, \& T. H. King (eds), The Proceedings of the LFG'12 Conference (pp. 490502), Stanford, CA: CSLI Publications.

Pulvermüller, F., \& Shtyrov, Y. (2003). Automatic processing of grammar in the human brain as revealed by the mismatch negativity. NeuroImage, 20(1), 159-172.

R core team. (2014). R: A Language and Environment for Statistical Computing. Vienna, Austria: R Foundation for Statistical Computing.

Riordan, B., Dye, M., \& Jones, M. N. (2015). Grammatical number processing and anticipatory eye movements are not tightly coordinated in English spoken language comprehension. Language Sciences, 590.

Robertson, E. K., Shi, R., \& Melançon, A. (2012). Toddlers Use the Number Feature in Determiners During Online Noun Comprehension. Child Development, 83(6), 2007-2018.

Roettger, T. B., \& Domahs, F. (2013). The spatial representation of grammatical number. Proceedings of the Annual Meeting of the Cognitive Science Society, 35(35).

Roettger, T. B., \& Domahs, F. (2015). Grammatical number elicits SNARC and MARC effects as a function of task demands. Quarterly Journal of Experimental Psychology, 68(6), 1231-1248. https://doi.org/10.1080/17470218.2014.979843

Sarnecka, B. W. (2014). On the relation between grammatical number and cardinal numbers in development. Frontiers in Psychology, 5, 1132. https://doi.org/10.3389/fpsyg.2014.01132 


\section{SYNTACTIC INFLUENCES ON NUMERICAL COGNITION}

Sarnecka, B. W., Kamenskaya, V. G., Ogura, T., Yamana, Y., \& Yudovina, J. B. (2004). Language as lens: Plurality marking and numeral learning in English, Japanese, and Russian. Retrieved from https://www.semanticscholar.org/paper/Language-as-lens\%3A-Plurality-marking-and-numeral-inSarnecka-Kamenskaya/42706653f7870be07acaded5ea4fa43de579bd65

Sarnecka, B. W., Kamenskaya, V. G., Yamana, Y., Ogura, T., \& Yudovina, Y. B. (2007). From grammatical number to exact numbers: Early meanings of 'one', 'two', and 'three' in English, Russian, and Japanese. Cognitive Psychology, 55(2), 136-168. https://doi.org/10.1016/J.COGPSYCH.2006.09.001

Schroeder, P. A., Nuerk, H.-C., \& Plewnia, C. (2017). Switching between Multiple Codes of SNARC-Like Associations: Two Conceptual Replication Attempts with Anodal tDCS in Sham-Controlled Cross-Over Design. Frontiers in Neuroscience, 11, 654. https://doi.org/10.3389/fnins.2017.00654

Schweppe, J. (2013). Distance Effects in Number Agreement. Discourse Processes, 50(8), 531-556.

Simons, D. J. (2014). The Value of Direct Replication. Perspectives on Psychological Science, 9(1), 76-80. https://doi.org/10.1177/1745691613514755

Świdziński, M. (2015). O frazie nominalnej liczebnikowej w pozycji podmiotu po raz kolejny. LingVaria, (19), 81-97. doi: 10.12797/LV.10.2015.19.05

Tanner, D., \& Bulkes, N. Z. (2015). Cues, quantification, and agreement in language comprehension. Psychonomic Bulletin \& Review, 22(6), 1753-1763.

van Dijck, J.-P., \& Fias, W. (2011). A working memory account for spatial-numerical associations. Cognition, 119(1), 114-119. https://doi.org/10.1016/J.COGNITION.2010.12.013

Wagenmakers, E.-J., Love, J., Marsman, M., Jamil, T., Ly, A., Verhagen, J., ... Morey, R. D. (2018). Bayesian inference for psychology. Part II: Example applications with JASP. Psychonomic Bulletin \& Review, 25(1), 58-76. https://doi.org/10.3758/s13423-017-1323-7

Wagers, M. W., Lau, E. F., \& Phillips, C. (2009). Agreement attraction in comprehension: Representations and processes. Journal of Memory and Language, 61(2), 206-237.

Weis, T., Nuerk, H.-C., \& Lachmann, T. (2018). Attention allows the SNARC effect to operate on multiple number lines. Scientific Reports, 8(1), 1-13. https://doi.org/10.1038/s41598-018-32174-y

Wood, G., Willmes, K., Nuerk, H.-C., \& Fischer, M. H. (2008). On the cognitive link between space and number: A meta-analysis of the SNARC effect. Psychology Science, 50(4), 489-525. 
SYNTACTIC INFLUENCES ON NUMERICAL COGNITION

Supplementary material A: Additional measures.

Three paper and pencil measurements were gathered as part of another research project, so the results are not reported in detail here: (1) LPS (a measure of fluid intelligence), subtest 3 of Leistungsprüfsystem 2 (Kreuzpointner et al., 2013); (2) AMAS - Abbreviated Math Anxiety Scale (Hopko et al., 2003); and (3) Speeded Arithmetic Task. Language groups included in the final analysis did not differ significantly on any of these three measures (LPS: $p=.129$, AMAS: $p=.061$, Speeded Arithmetic Task: $p=.271)$. Additionally, participants answered questions on: computer gaming (amount per week), sleep quality (in the last month), math and language grades (GCSE / A-level), finger counting routines (starting hand), field of study, languages spoken, and periods longer than 6 weeks living in another language environment (see Cipora et al., 2019, for similar control questions). These questions and the participant answers were not considered in the analyses presented in this paper. 
Supplementary material B: Excluded participants due to accuracy issues.

\begin{tabular}{|c|c|c|c|c|c|c|c|c|c|c|}
\hline \multirow[t]{4}{*}{ No } & \multirow[t]{4}{*}{ Lang. } & \multirow{4}{*}{$\begin{array}{l}\text { Total } \\
\text { acc }\end{array}$} & \multicolumn{8}{|c|}{ Blockwise acc } \\
\hline & & & \multicolumn{4}{|c|}{ Grammatical number judgement } & \multicolumn{4}{|c|}{ Parity judgement } \\
\hline & & & \multicolumn{2}{|c|}{ Even \& } & \multicolumn{2}{|c|}{ Odd \& } & \multicolumn{2}{|c|}{ Even \& } & \multicolumn{2}{|c|}{ Odd \& } \\
\hline & & & plural & singular & plural & singular & plural & singular & plural & singular \\
\hline 1 & $\mathrm{E}$ & 0.805 & 0.906 & 0.930 & 0.938 & $0.078 * *$ & 0.898 & 0.906 & 0.898 & 0.883 \\
\hline 2 & $\mathrm{E}$ & $0.694 *$ & $0.633 * *$ & $0.493 * *$ & 0.836 & 0.727 & 0.680 & 0.664 & 0.680 & 0.844 \\
\hline 3 & $\mathrm{E}$ & 0.758 & $0.648^{* * *}$ & 0.773 & 0.883 & 0.813 & $0.594 * *$ & 0.836 & 0.828 & 0.688 \\
\hline 4 & $\mathrm{G}$ & $0.702 *$ & 0.922 & 0.898 & 0.891 & $0.063 * *$ & 1.000 & 0.992 & 0.820 & $0.031 * *$ \\
\hline 5 & $\mathrm{G}$ & 0.781 & 0.789 & 0.875 & 0.719 & 0.906 & 0.719 & 0.750 & $0.617 * *$ & 0.875 \\
\hline 6 & $\mathrm{G}$ & 0.842 & 0.961 & 0.961 & 0.961 & 0.977 & 0.961 & 0.953 & $0.078 * *$ & 0.883 \\
\hline 7 & G & $0.738^{*}$ & $0.617 * *$ & $0.641 * *$ & 0.875 & 0.852 & $0.602 * *$ & $0.461 * *$ & 0.930 & 0.930 \\
\hline 8 & $\mathrm{G}$ & $0.553^{*}$ & $0.547 * *$ & $0.250 * *$ & 0.773 & $0.547 * *$ & 0.758 & 0.891 & $0.180 * *$ & 0.477 ** \\
\hline 9 & G & $0.728^{*}$ & 0.953 & 0.914 & 0.969 & $0.086^{* * *}$ & 0.891 & 0.953 & 0.891 & $0.164 * *$ \\
\hline 10 & $\mathrm{G}$ & 0.805 & 0.906 & 0.867 & 0.914 & 0.922 & 0.891 & 0.813 & $0.250 * *$ & 0.875 \\
\hline 11 & $\mathrm{G}$ & $0.731 *$ & 0.953 & 0.969 & $0.039 * *$ & 0.906 & 0.953 & 0.992 & $0.094 * *$ & 0.945 \\
\hline 12 & $\mathrm{G}$ & 0.821 & 0.914 & 0.891 & 0.930 & 0.930 & 0.977 & 0.961 & $0.055 * *$ & 0.914 \\
\hline 13 & $\mathrm{G}$ & 0.755 & $0.477 * *$ & 0.703 & 0.930 & 0.922 & $0.563 * *$ & 0.688 & 0.867 & 0.891 \\
\hline 14 & $\mathrm{G}$ & 0.754 & 0.797 & 0.875 & 0.797 & $0.547 * *$ & 0.750 & 0.859 & 0.859 & $0.547 * *$ \\
\hline 15 & $\mathrm{G}$ & 0.855 & 0.922 & 0.914 & 0.953 & 0.789 & 0.898 & 0.883 & 0.891 & $0.594 * *$ \\
\hline 16 & $\mathrm{P}$ & $0.713^{*}$ & $0.625^{* *}$ & $0.281 * *$ & 0.883 & 0.813 & 0.648 ** & 0.656 & 0.883 & 0.914 \\
\hline 17 & $\mathrm{P}$ & 0.771 & $0.477 * *$ & 0.922 & 0.867 & 0.906 & $0.500^{* *}$ & 0.906 & 0.797 & 0.789 \\
\hline 18 & $\mathrm{P}$ & 0.836 & 0.898 & 0.906 & 0.852 & $0.367 * *$ & 0.891 & 0.945 & 0.961 & 0.867 \\
\hline 19 & $\mathrm{P}$ & 0.838 & 0.961 & 0.984 & 0.852 & 0.945 & 0.977 & 0.961 & $0.102 * *$ & 0.922 \\
\hline 20 & $\mathrm{P}$ & $0.722 *$ & 0.922 & 0.922 & $0.531 * *$ & $0.445 * *$ & 0.836 & 0.984 & 0.664 & $0.469 * *$ \\
\hline 21 & $\mathrm{P}$ & 0.843 & 0.953 & $0.086 * *$ & 0.984 & 0.961 & 0.977 & 0.914 & 0.945 & 0.922 \\
\hline 22 & $\mathrm{P}$ & $0.694 *$ & $0.555^{* *}$ & $0.500 * *$ & $0.547 * *$ & $0.492 * *$ & 0.875 & 0.805 & 0.938 & 0.844 \\
\hline 23 & $\mathrm{P}$ & $0.715^{*}$ & 0.961 & 0.914 & 0.914 & $0.094 * *$ & 0.922 & 0.891 & 0.906 & $0.117 * *$ \\
\hline 24 & $\mathrm{P}$ & 0.759 & 0.836 & 0.898 & 0.719 & 0.938 & 0.883 & 0.852 & $0.164 * *$ & 0.781 \\
\hline 25 & $P$ & 0.767 & 0.742 & 0.820 & 0.719 & 0.820 & 0.867 & 0.828 & 0.688 & $0.648 * *$ \\
\hline 26 & $\mathrm{P}$ & 0.848 & $0.547 * *$ & 0.914 & 0.938 & 0.984 & 0.742 & 0.930 & 0.891 & 0.836 \\
\hline 27 & $\mathrm{P}$ & $0.698^{*}$ & 0.844 & 0.797 & $0.617 * *$ & $0.594 * *$ & 0.828 & 0.844 & $0.477 * *$ & $0.586^{* * *}$ \\
\hline 28 & $P$ & 0.863 & 0.961 & $0.078 * *$ & 0.977 & 0.977 & 0.992 & 0.945 & 0.993 & 0.984 \\
\hline 29 & $\mathrm{P}$ & 0.750 & 0.813 & $0.203 * *$ & 0.703 & 0.797 & 0.820 & 0.852 & 0.906 & 0.906 \\
\hline 30 & $P$ & $0.438 *$ & $0.500 * *$ & $0.477 * *$ & $0.289 * *$ & $0.398 * *$ & 0.844 & $0.648 * *$ & $0.188 * *$ & $0.164 * *$ \\
\hline 31 & $\mathrm{P}$ & 0.744 & 0.977 & 0.992 & 0.992 & 1.000 & $0.492 * *$ & 0.500 & 0.500 & 0.500 \\
\hline 32 & $\mathrm{P}$ & 0.769 & 0.891 & $0.273 * *$ & 0.703 & 0.852 & 0.891 & 0.844 & 0.813 & 0.883 \\
\hline
\end{tabular}

Note. Accuracy $=$ general accuracy over all trials and tasks. Blockwise accuracy $=$ per task type and per response to task assignment, response to task assignments refer to right-hand responses. $*=$ general accuracy $<75 \%, * *=$ accuracy rate in response to task assignment $<66 \%$. 


\section{Supplementary material C: Bin analysis of RT quartiles in both tasks.}

In accordance Roettger and Domahs (2013), the same ANOVA model as in the main text was applied to RT bins for both the parity judgment and the grammatical number judgment task. In the analysis we focused mostly on the numerical (in case of parity judgment), and the grammatical (in case of grammatical number judgment) SNARC effects. We also looked at whether language modulated these interactions. Other effects were not of interest. Nevertheless, we report full ANOVA results.

\section{$\underline{\text { Parity judgment task }}$}

Bin 1 (i.e., fastest $25 \%$ responses)

\begin{tabular}{lllll}
\hline Factors & df & $F$ & $p$ & $\eta_{\mathrm{p}}{ }^{2}$ \\
\hline Language & 2,95 & 1.04 & .357 & .02 \\
Direct grammatical number & 1,95 & 0.60 & .441 & .01 \\
Direct grammatical number $\times$ Language & 2,95 & 0.81 & .446 & .02 \\
Response side & 1,95 & 1.99 & .161 & .02 \\
Response side $\times$ Language & 2,95 & 0.77 & .465 & .02 \\
Unit magnitude (Indirect grammatical number) & 1,95 & 1.32 & .254 & .01 \\
Unit magnitude (Indirect grammatical number) $\times$ Language & $\mathbf{2 , 9 5}$ & $\mathbf{3 . 1 9}$ & $\mathbf{. 0 4 6}$ & $\mathbf{. 0 6}$ \\
Direct grammatical number $\times$ Response side & 1,95 & 0.25 & .616 & .00 \\
$\begin{array}{l}\text { Direct grammatical number } \times \text { Response side } \times \text { Language } \\
\text { Direct grammatical number } \times \text { Unit magnitude (Indirect }\end{array}$ & 2,95 & 1.91 & .154 & .04 \\
grammatical number) & 1,95 & 1.08 & .302 & .01 \\
Direct grammatical number $\times$ Unit magnitude (Indirect & 2,95 & 0.48 & .618 & .01 \\
grammatical number) $\times$ Language & & & & .02 \\
Response side $\times$ Unit magnitude (Indirect grammatical number) & 1,95 & 2.07 & .153 & .05 \\
$\begin{array}{l}\text { Response side } \times \text { Unit magnitude (Indirect grammatical number) } \times \\
\text { Language }\end{array}$ & 2,95 & 2.60 & .079 \\
$\begin{array}{l}\text { Direct grammatical number } \times \text { Response side } \times \text { Unit magnitude } \\
\text { (Indirect grammatical number) }\end{array}$ & 1,95 & 0.00 & .958 & .00 \\
$\begin{array}{l}\text { Direct grammatical number } \times \text { Response side } \times \text { Unit magnitude } \\
\text { (Indirect grammatical number) } \times \text { Language }\end{array}$ & 2,95 & 0.35 & .705 & .01
\end{tabular}

Note. Type III Sum of Squares, Significant effects are marked with bold.

\section{Bin 2}

\begin{tabular}{lllll}
\hline Factors & $\mathrm{df}$ & $F$ & $p$ & $\eta_{\mathrm{p}}{ }^{2}$ \\
\hline Language & 2,95 & 0.93 & .397 & .02 \\
Direct grammatical number & 1,95 & 1.24 & .269 & .01 \\
Direct grammatical number $\times$ Language & 2,95 & 2.41 & .095 & .05 \\
Response side & 1,95 & 1.97 & .164 & .02 \\
Response side $\times$ Language & 2,95 & 0.10 & .904 & .00 \\
Unit magnitude (Indirect grammatical number) & 1,95 & 2.64 & .107 & .03 \\
Unit magnitude (Indirect grammatical number) $\times$ Language & 2,95 & 1.64 & .200 & .03 \\
Direct grammatical number $\times$ Response side & $\mathbf{1 , 9 5}$ & $\mathbf{6 . 4 7}$ & $\mathbf{. 0 1 3}$ & $\mathbf{. 0 6}$ \\
Direct grammatical number $\times$ Response side $\times$ Language & 2,95 & 1.34 & .268 & .03 \\
Direct grammatical number $\times$ Unit magnitude (Indirect & 1,95 & 1.39 & .241 & .01
\end{tabular}
grammatical number) 
Direct grammatical number $\times$ Unit magnitude (Indirect

2,95

0.67

.514

.01

grammatical number) $\times$ Language

Response side $\times$ Unit magnitude (Indirect grammatical number)

1,95

0.03

.872

.00

Response side $\times$ Unit magnitude (Indirect grammatical number) $\times$

2,95

2.02

.139

.04

Language

Direct grammatical number $\times$ Response side $\times$ Unit magnitude

1,95

0.16

.692

.00

Direct grammatical number $\times$ Response side $\times$ Unit magnitude

2,95

0.80

.451

.02

(Indirect grammatical number) $\times$ Language

Note. Type III Sum of Squares, Significant effects are marked with bold.

\section{Bin 3}

\begin{tabular}{|c|c|c|c|c|}
\hline Factors & df & $F$ & $p$ & $\eta_{\mathrm{p}}^{2}$ \\
\hline Language & 2,95 & 1.46 & .238 & .00 \\
\hline Direct grammatical number & 1,95 & 0.20 & .652 & .00 \\
\hline Direct grammatical number $\times$ Language & 2,95 & 0.29 & .752 & .01 \\
\hline Response side & 1,95 & 2.00 & .161 & .02 \\
\hline Response side $\times$ Language & 2,95 & 0.84 & .435 & .02 \\
\hline Unit magnitude (Indirect grammatical number) & 1,95 & 0.01 & .906 & .00 \\
\hline Unit magnitude (Indirect grammatical number) $\times$ Language & 2,95 & 0.15 & .860 & .00 \\
\hline Direct grammatical number $\times$ Response side & 1,95 & 1.37 & .245 & .01 \\
\hline Direct grammatical number $\times$ Response side $\times$ Language & 2,95 & 0.00 & .997 & .00 \\
\hline $\begin{array}{l}\text { Direct grammatical number } \times \text { Unit magnitude }(\text { Indirect } \\
\text { grammatical number) }\end{array}$ & 1,95 & 0.96 & .329 & .01 \\
\hline $\begin{array}{l}\text { Direct grammatical number } \times \text { Unit magnitude }(\text { Indirect } \\
\text { grammatical number }) \times \text { Language }\end{array}$ & 2,95 & 1.05 & .354 & .02 \\
\hline Response side $\times$ Unit magnitude (Indirect grammatical number) & 1,95 & 0.03 & .861 & .00 \\
\hline $\begin{array}{l}\text { Response side } \times \text { Unit magnitude (Indirect grammatical number) } \times \\
\text { Language }\end{array}$ & 2,95 & 0.04 & .958 & .04 \\
\hline $\begin{array}{l}\text { Direct grammatical number } \times \text { Response side } \times \text { Unit magnitude } \\
\text { (Indirect grammatical number) }\end{array}$ & 1,95 & 1.95 & .165 & .02 \\
\hline $\begin{array}{l}\text { Direct grammatical number } \times \text { Response side } \times \text { Unit magnitude } \\
\text { (Indirect grammatical number) } \times \text { Language }\end{array}$ & 2,95 & 2.29 & .107 & .05 \\
\hline
\end{tabular}

(Indirect grammatical number) $\times$ Language

Note. Type III Sum of Squares, Significant effects are marked with bold.

Bin 4 (i.e., slowest 25\% responses)

\begin{tabular}{|c|c|c|c|c|}
\hline Factors & df & $F$ & $p$ & $\eta_{\mathrm{p}}^{2}$ \\
\hline Language & 2,95 & 1.91 & .153 & .04 \\
\hline Direct grammatical number & 1,95 & 0.09 & .764 & .00 \\
\hline Direct grammatical number $\times$ Language & 2,95 & 0.36 & 697 & .01 \\
\hline Response side & 1,95 & 0.62 & .433 & .01 \\
\hline Response side $\times$ Language & 2,95 & 0.93 & .397 & .02 \\
\hline Unit magnitude (Indirect grammatical number) & 1,95 & 3.07 & .083 & .03 \\
\hline Unit magnitude (Indirect grammatical number) $\times$ Language & 2,95 & 0.84 & .436 & .02 \\
\hline Direct grammatical number $\times$ Response side & 1,95 & 1.43 & .234 & .01 \\
\hline Direct grammatical number $\times$ Response side $\times$ Language & 2,95 & 1.11 & .335 & .02 \\
\hline $\begin{array}{l}\text { Direct grammatical number } \times \text { Unit magnitude }(\text { Indirect } \\
\text { grammatical number) }\end{array}$ & 1,95 & 0.12 & .734 & .00 \\
\hline $\begin{array}{l}\text { Direct grammatical number } \times \text { Unit magnitude }(\text { Indirect } \\
\text { grammatical number }) \times \text { Language }\end{array}$ & 2,95 & 0.87 & .423 & .02 \\
\hline Response side $\times$ Unit magnitude (Indirect grammatical number) & 1,95 & 0.02 & .893 & .00 \\
\hline $\begin{array}{l}\text { Response side } \times \text { Unit magnitude (Indirect grammatical number) } \times \\
\text { Language }\end{array}$ & 2,95 & 0.40 & .672 & .01 \\
\hline $\begin{array}{l}\text { Direct grammatical number } \times \text { Response side } \times \text { Unit magnitude } \\
\text { (Indirect grammatical number) }\end{array}$ & 1,95 & 0.01 & .928 & .00 \\
\hline $\begin{array}{l}\text { Direct grammatical number } \times \text { Response side } \times \text { Unit magnitude } \\
\text { (Indirect grammatical number) } \times \text { Language }\end{array}$ & 2,95 & 2.01 & .140 & .04 \\
\hline
\end{tabular}

Note. Type III Sum of Squares, Significant effects are marked with bold. 
$\underline{\text { Grammatical number judgment }}$

Bin 1 (i.e., fastest 25\% responses)

\begin{tabular}{|c|c|c|c|c|}
\hline Factors & df & $F$ & $p$ & $\eta_{p}^{2}$ \\
\hline Language & 2,95 & 1.56 & .215 & .03 \\
\hline Direct grammatical number & 1,95 & 0.10 & .747 & .00 \\
\hline Direct grammatical number $\times$ Language & 2,95 & 0.60 & .550 & .01 \\
\hline Response side & 1,95 & $<.01$ & .996 & .00 \\
\hline se side $\times$ Language & 2,95 & 0.64 & .531 & .01 \\
\hline Unit Magnitude (Indirect grammatical number) & 1,95 & 0.02 & 903 & .00 \\
\hline . & 2,95 & 1.61 & .206 & .03 \\
\hline Direct & 1,95 & 4.33 & .040 & .04 \\
\hline Direct grammatical number $\times$ Response side $\times$ Language & 2,95 & 0.35 & .709 & .01 \\
\hline $\begin{array}{l}\text { Direct grammatical number } \times \text { Unit Magnitude (Indirect grammatical } \\
\text { number) }\end{array}$ & 1,95 & 0.07 & .789 & .00 \\
\hline $\begin{array}{l}\text { Direct grammatical number } \times \text { Unit Magnitude (Indirect grammatical } \\
\text { number) } \times \text { Language }\end{array}$ & 2,95 & 1.96 & 147 & .04 \\
\hline Response side × Unit Magnitude (Indirect grammatical number) & 1,95 & 0.14 & .708 & .00 \\
\hline $\begin{array}{l}\text { Response side } \times \text { Unit Magnitude (Indirect grammatical number) } \times \\
\text { Language }\end{array}$ & 2,95 & 0.47 & .624 & .01 \\
\hline $\begin{array}{l}\text { Direct grammatical number } \times \text { Response side } \times \text { Unit Magnitude (Indirect } \\
\text { grammatical number) }\end{array}$ & 1,95 & 4.51 & .036 & .05 \\
\hline $\begin{array}{l}\text { Direct grammatical number } \times \text { Response side } \times \text { Unit Magnitude } \\
\text { (Indirect grammatical number }) \times \text { Language }\end{array}$ & 2,95 & 3.31 & .041 & .07 \\
\hline
\end{tabular}

Note. Type 3 Sums of Squares, Significant effects are marked with bold.

In this condition, the critical Direct grammatical number $\times$ Response side interaction was significant. Specifically, a grammatical MARC effect was observed (cf. Figure B1). However, it was not modulated by language.

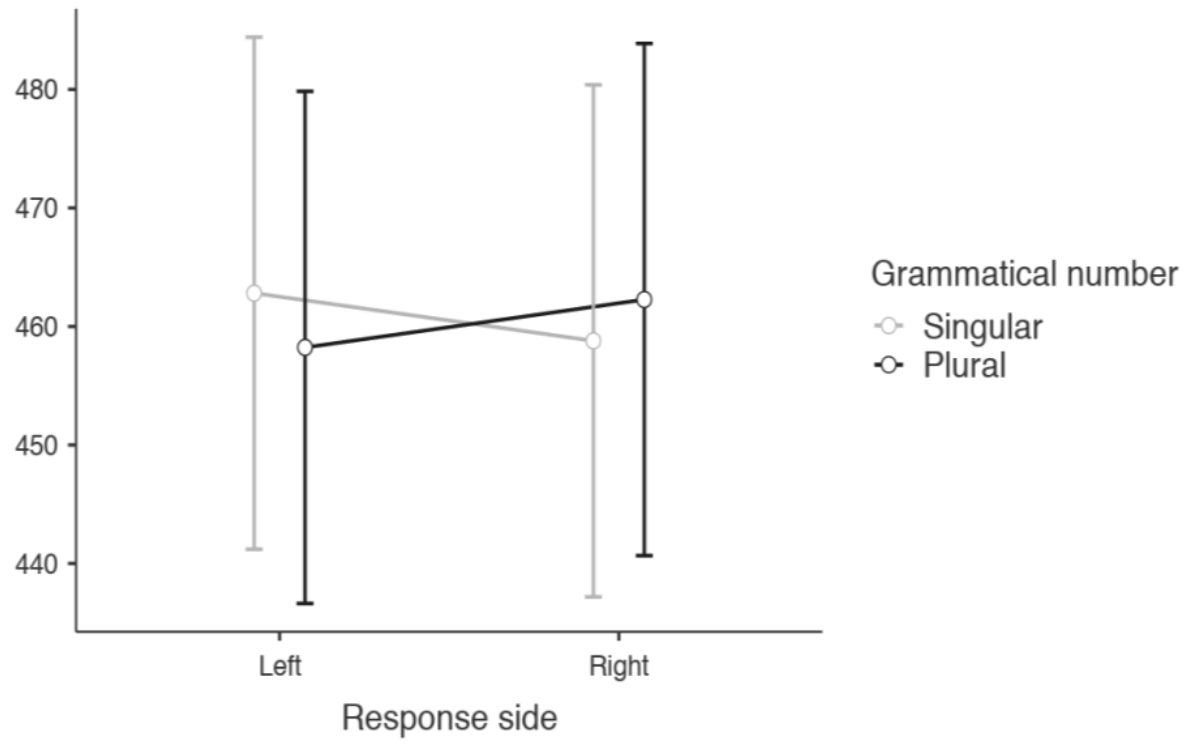

Figure C1. The Direct grammatical number $\times$ Response side interaction. Responses to a singular verb were faster with the right hand, and responses to a plural verb were faster with the left, indicating the presence of a grammatical MARC effect. 
Bin 2

\begin{tabular}{lrrrr}
\hline Factors & df & $F$ & $p$ & $\eta^{2} p$ \\
\hline Language & $\mathbf{2 , 9 5}$ & $\mathbf{3 . 4 8}$ & $\mathbf{. 0 3 5}$ & $\mathbf{. 0 7}$ \\
Direct grammatical number & 1,95 & 2.03 & .158 & .02 \\
Direct grammatical number $\times$ Language & 2,95 & 0.47 & .627 & .01 \\
Response side & 1,95 & 0.00 & .948 & .00 \\
Response side $\times$ Language & 2,95 & 0.47 & .628 & .01 \\
Unit Magnitude (Indirect grammatical number) & 1,95 & 1.94 & .167 & .02 \\
Unit Magnitude (Indirect grammatical number) $\times$ Language & 2,95 & 1.76 & .178 & .04 \\
Direct grammatical number $\times$ Response side & 1,95 & 0.20 & .654 & .00 \\
$\begin{array}{l}\text { Direct grammatical number } \times \text { Response side } \times \text { Language } \\
\text { Direct grammatical number } \times \text { Unit Magnitude (Indirect }\end{array}$ & 2,95 & 0.09 & .911 & .00 \\
grammatical number) & $\mathbf{1 , 9 5}$ & $\mathbf{6 . 2 8}$ & $\mathbf{. 0 1 4}$ & $\mathbf{. 0 6}$ \\
$\begin{array}{l}\text { Direct grammatical number } \times \text { Unit Magnitude (Indirect grammatical } \\
\text { number) } \times \text { Language }\end{array}$ & 2,95 & 1.00 & .373 & .02 \\
$\begin{array}{l}\text { Response side } \times \text { Unit Magnitude (Indirect grammatical number) } \\
\text { Response side } \times \text { Unit Magnitude (Indirect grammatical number) } \times\end{array}$ & 1,95 & 0.00 & .946 & .00 \\
Language & 2,95 & 1.18 & .312 & .02 \\
$\begin{array}{l}\text { Direct grammatical number } \times \text { Response side } \times \text { Unit Magnitude (Indirect } \\
\text { grammatical number) }\end{array}$ & 1,95 & 0.35 & .558 & .00 \\
$\begin{array}{l}\text { Direct grammatical number } \times \text { Response side } \times \text { Unit Magnitude (Indirect } \\
\text { grammatical number) } \times \text { Language }\end{array}$ & 2,95 & 2.04 & .136 & .04
\end{tabular}

Note. Type 3 Sums of Squares, Significant effects are marked with bold.

\section{Bin 3}

\begin{tabular}{lllll}
\hline Factors & df & $F$ & $p$ & $\eta^{2}$ p \\
\hline Language & $\mathbf{2 , 9 5}$ & $\mathbf{3 . 7 9}$ & $\mathbf{. 0 2 6}$ & $\mathbf{. 0 7}$ \\
Direct grammatical number & 1,95 & 2.89 & .093 & .03 \\
Direct grammatical number $\times$ Language & $\mathbf{2 , 9 5}$ & $\mathbf{3 . 8 1}$ & $\mathbf{. 0 2 6}$ & $\mathbf{. 0 7}$ \\
Response side & 1,95 & 0.63 & .431 & .01 \\
Response side $\times$ Language & 2,95 & 0.50 & .605 & .01 \\
Unit Magnitude (Indirect grammatical number) & 1,95 & 0.47 & .492 & .00 \\
Unit Magnitude (Indirect grammatical number) $\times$ Language & 2,95 & 0.59 & .559 & .01 \\
Direct grammatical number $\times$ Response side & 1,95 & 0.22 & .641 & .00 \\
$\begin{array}{l}\text { Direct grammatical number } \times \text { Response side } \times \text { Language } \\
\text { Direct grammatical number } \times \text { Unit Magnitude (Indirect grammatical } \\
\text { number) }\end{array}$ & 2,95 & 1.22 & .300 & .03 \\
Direct grammatical number $\times$ Unit Magnitude (Indirect grammatical & $\mathbf{4 . 0 1}$ & $\mathbf{. 0 4 8}$ & $\mathbf{. 0 4}$ \\
number) $\times$ Language & & $\mathbf{3 . 3 2}$ & $\mathbf{. 0 4 0}$ & $\mathbf{. 0 7}$ \\
$\begin{array}{l}\text { Response side } \times \text { Unit Magnitude (Indirect grammatical number) } \\
\text { Response side } \times \text { Unit Magnitude (Indirect grammatical number) } \times\end{array}$ & 1,95 & 0.27 & .608 & .00 \\
Language & 2,95 & 0.89 & .416 & .02 \\
$\begin{array}{l}\text { Direct grammatical number } \times \text { Response side } \times \text { Unit Magnitude (Indirect } \\
\text { grammatical number) }\end{array}$ & 1,95 & 0.97 & .327 & .01 \\
$\begin{array}{l}\text { Direct grammatical number } \times \text { Response side } \times \text { Unit Magnitude (Indirect } \\
\text { grammatical number) } \times \text { Language }\end{array}$ & 2,95 & 0.64 & .530 & .01 \\
\hline
\end{tabular}

Note. Type 3 Sums of Squares, Significant effects are marked with bold.

Bin 4 (i.e., slowest 25\% responses)

\begin{tabular}{llllr}
\hline Factors & df & $F$ & $p$ & $\eta^{2} p$ \\
\hline Language & $\mathbf{2 , 9 5}$ & $\mathbf{4 . 3 4}$ & $\mathbf{. 0 1 6}$ & $\mathbf{. 0 8}$ \\
Direct grammatical number & $\mathbf{1 , 9 5}$ & $\mathbf{4 . 7 3}$ & $\mathbf{. 0 3 2}$ & $\mathbf{. 0 5}$ \\
Direct grammatical number $\times$ Language & 2,95 & 0.90 & .411 & .02
\end{tabular}


Response side

Response side $\times$ Language

$\begin{array}{llll}1,95 & 0.00 & .963 & .00\end{array}$

Unit Magnitude (Indirect grammatical number)

$\begin{array}{llll}2,95 & 1.82 & .167 & .04\end{array}$

Unit Magnitude (Indirect grammatical number) $\times$ Language

$\begin{array}{llll}1,95 & 0.72 & .399 & .01\end{array}$

Direct grammatical number $\times$ Response side

$\begin{array}{llll}2,95 & 0.14 & .872 & .00\end{array}$

$\begin{array}{llll}1,95 & 0.32 & .570 \quad .00\end{array}$

Direct grammatical number $\times$ Response side $\times$ Language
Direct grammatical number $\times$ Unit Magnitude (Indirect grammatical number)

Direct grammatical number $\times$ Unit Magnitude (Indirect grammatical number)

$2,95 \quad 0.40 \quad .671 \quad .01$

$\begin{array}{llll}1,95 & 2.51 \quad .116 \quad .03\end{array}$

$\times$ Language

Response side $\times$ Unit Magnitude (Indirect grammatical number) $\quad \begin{array}{llll}0.95 & 3.60 & .061 & .04\end{array}$

Response side $\times$ Unit Magnitude (Indirect grammatical number) $\times$ Language $\quad \begin{array}{lllll}2,95 & 0.61 & .546 & .01\end{array}$

Direct grammatical number $\times$ Response side $\times$ Unit Magnitude (Indirect $\quad \begin{array}{llllll}0.363 & 1,95 & 0.83 & .01\end{array}$

grammatical number)

Direct grammatical number $\times$ Response side $\times$ Unit Magnitude (Indirect $\quad \begin{array}{lllll}0.43 & & 2,950 & 0.95 & 0.43\end{array}$

grammatical number) $\times$ Language

Note. Type 3 Sums of Squares, Significant effects are marked with bold.

\section{$\underline{\text { Conclusions }}$}

Partially replicating Roettger and Domahs (2013), we found a significant grammatical

MARC effect for the fastest responses. Plural Direct grammatical number was responded to faster with the left hand and the singular faster with the right hand. However, we did not observe a grammatical SNARC effect when the longest responses were analyzed. Crucially, the effect was not modulated by language. 